\title{
FREE VIBRATION AND BUCKLING ANALYSIS OF TWO DIRECTIONAL FUNCTIONALLY GRADED BEAMS USING A FOUR-UNKNOWN SHEAR AND NORMAL DEFORMABLE BEAM THEORY
}

\author{
Armağan KARAMANLI * \\ Department of Mechatronics, Faculty of Engineering and Architecture, İstanbul Gelişim University, \\ 34215, İstanbul, Turkey
}

\begin{abstract}
This study presents the free vibration and buckling behavior of two directional (2D) functionally graded beams (FGBs) under arbitrary boundary conditions (BCs) for the first time. A four-known shear and normal deformation (Quasi-3D) theory where the axial and transverse displacements are assumed to be cubic and parabolic variation through the beam depth is employed based on the framework of the Ritz formulation. The equations of motion are derived from Lagrange's equations. The developed formulation is validated by solving a homogeneous beam problem and considering different aspect ratios and boundary conditions. The obtained numerical results in terms of dimensionless fundamental frequencies and dimensionless first critical buckling loads are compared with the results from previous studies for convergence studies. The material properties of the studied problems are assumed to vary along both longitudinal and thickness directions according to the power-law distribution. The axial, bending, shear and normal displacements are expressed in polynomial forms with the auxiliary functions which are necessary to satisfy the boundary conditions. The effects of shear deformation, thickness stretching, material distribution, aspect ratios and boundary conditions on the free vibration frequencies and critical buckling loads of the 2D-FGBs are investigated.
\end{abstract}

Keywords: 2D Functionally Graded Beam, Ritz Method, Quasi-3D Theory, Vibration, Buckling

\section{INTRODUCTION}

Functionally Graded Materials (FGMs) are a class of advanced composite materials whose material properties vary continuously in the desired directions. Since the use of this kind of materials avoids the stress concentration, cracking and interface problems through the layer interfaces in conventional composites, they have been using in many modern engineering applications such as military, aerospace, nuclear energy, biomedical, automotive, marine and civil engineering. Moreover, FGMs have lower transverse shear stresses and high resistance to temperature shocks. Due to their striking features, researchers have been developed the advanced theories and analysis methods to predict and to understand more precisely the behaviors of FGMs.

Since the significant shear deformation effects occur especially in thick/moderately thick conventional functionally graded beams (FGBs), three main theories that are first-order shear deformable beam theory (FSBT), higher-order shear deformable beam theory (HSBT) and shear and normal deformable beam theory (SNDBT) namely Quasi 3-D theory are popular among the researchers. The simplest model is the FSBT which does not satisfy the zero traction boundary conditions at the top and the bottom surfaces of the beam; however a shear correction factor is required [1-6]. This leads to the proposition of the HSBT theories which refined the distribution of the transverse shear stress; ultimately no shear correction factor is needed [7-19]. On the other hand, HSBT theories do not consider the normal strain effect which becomes very important and should be considered for thick conventional FGBs. Hence, quasi 3-D theories in which the shear and normal deformations taking into account are developed based on a higher order variation of both axial and transverse displacements [20-30].

*Corresponding Author: afkaramanli@gelisim.edu.tr

Receiving Date: 12 December 2017 Publishing Date: 29 June 2018 
The conventional FGBs (or 1D-FGBs) formed by changing material properties only in one direction may not satisfy required specifications such as the temperature and stress distributions in two or three direction for aerospace craft and shuttles [31]. In recent years, researchers have been devoted some studies about a new type FGB whose material properties varying in two or three directions to overcome this deficiency of the conventional FGBs. A methodology is presented for the simulation and optimization of the vibration response of bidirectional functionally graded beams based on the Element Free Galerkin method in [32]. The bending and thermal deformations of FGBs with various end conditions are investigated by using the state-space based differential quadrature method to obtain the semi-analytical elasticity solutions in [33]. The static and free vibration analysis two-directional FGBs are studied by presenting a symplectic elasticity solution in [34]. Free and forced vibration of Timoshenko two directional functionally graded beams under a moving load is investigated in [35] for the case that the material properties of the 2D-FGB vary exponentially through the length and height directions. Based on the power-law distribution of the material properties, the buckling of Timoshenko beams composed of two directional FGM is studied in [36]. The static behavior of the two directional FGBs by using various beam theories is presented in [37]. The fully coupled thermo-mechanical behavior of bi-directional functionally graded material (FGM) beam structures is studied via finite element method in [38]. An analytical solution for the static deformations of the bi-directional functionally graded thick circular beams is developed based on a new shear deformation theory with a logarithmic function in the postulated expression for the circumferential displacement in [39] The flexure behavior of the two directional FG sandwich beams by using a quasi-3D theory and a meshless method is studied in [40]. Elasticity solutions of 2D-FG rotating annular and solid disks with variable thickness are presented in [41]. The vibration responses of 2D-FG Timoshenko beams excited by a moving concentrated load are investigated in [42]. In a very recent work by Haciyev et al., the bending vibration of bi-directionally exponentially orthotropic plates resting on the Pasternak elastic foundation is studied based on the classical plate theory via Galerkin method [43].

It is clear from above discussions that the publications related to free vibration and buckling behavior of the two-directional FGBs are very limited according to the best of author knowledge. Moreover, there is no reported work on the dynamic and static analysis of the two directional FBGs based on a shear and normal deformation theory employing power-law material distribution in the problem domain. Since, thickness-stretching effect becomes very important especially for the thick two directional FGBs, a shear and normal deformation theory should be considered for this complicated problem with various end conditions, aspect ratios and gradation exponents. The main novelty of this paper is that the analytical solutions are presented for the free vibration and buckling behavior of the two directional FGBs based on a quasi-3D theory for the first time. The effects of shear deformation, thickness stretching, material distribution, aspect ratios and boundary conditions on the free vibration frequencies and critical buckling loads of the two directional functionally graded beams are discussed.

\section{THEORY AND FORMULATION}

\subsection{Two Directional Functionally Graded Beams}

Consider a two-directional functionally graded beam with its dimensions and coordinate as shown in Figure 1. The material properties vary both longitudinal and thickness directions. The origin of the coordinate system is at the midpoint of the beam. In this study, the rule of mixture is used to find the effective material properties at a point. The effective material properties of the beam, Young's modulus $\mathrm{E}$ and shear modulus $\mathrm{G}$ can be given by

$$
\begin{gathered}
E(x, z)=E_{1} V_{1}(x, z)+E_{2} V_{2}(x, z) \\
G(x, z)=G_{1} V_{1}(x, z)+G_{2} V_{2}(x, z) \\
\rho(x, z)=\rho_{1} V_{1}(x, z)+\rho_{2} V_{2}(x, z)
\end{gathered}
$$




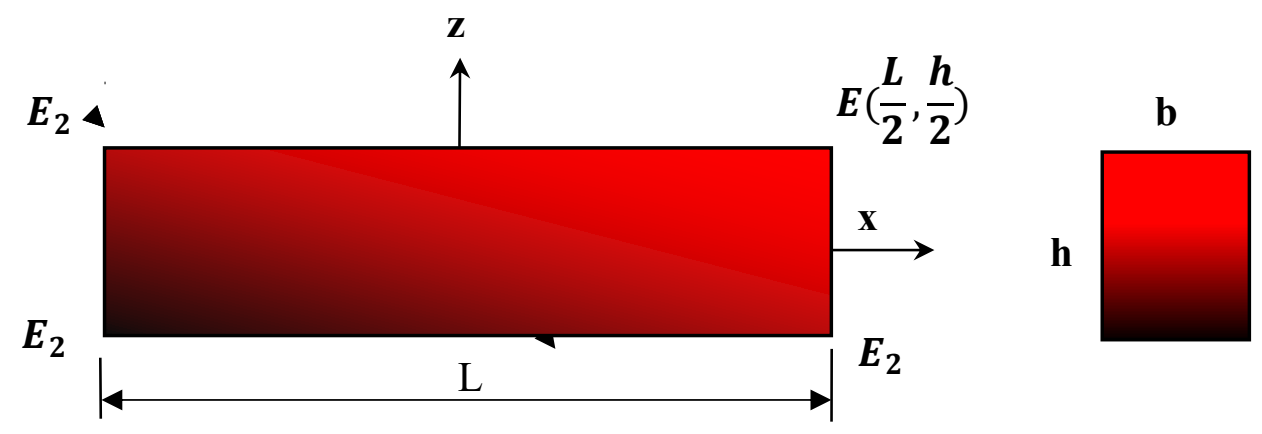

Figure 1. Geometry and coordinate of a two-directional FGB

According to the power law form, the volume fraction of the constitute 1 can be given by

$$
V_{1}(x, z)=\left(\frac{1}{2}+\frac{x}{L}\right)^{p_{x}}\left(\frac{1}{2}+\frac{z}{h}\right)^{p_{z}}
$$

where $p_{x}$ and $p_{z}$ are the gradation exponents (power-law index) which determine the material properties through the thickness $(\mathrm{h})$ and length of the beam $(\mathrm{L})$, respectively. When the $p_{x}$ and $p_{z}$ are set to zero then the beam becomes homogeneous. The effective material properties can be found by using the Eqs. (1), (2) and (3) as follows,

$$
\begin{aligned}
& E(x, z)=\left(E_{1}-E_{2}\right)\left(\frac{1}{2}+\frac{x}{L}\right)^{p_{x}}\left(\frac{1}{2}+\frac{z}{h}\right)^{p_{z}}+E_{2} \\
& G(x, z)=\left(G_{1}-G_{2}\right)\left(\frac{1}{2}+\frac{x}{L}\right)^{p_{x}}\left(\frac{1}{2}+\frac{z}{h}\right)^{p_{z}}+G_{2} \\
& \rho(x, z)=\left(\rho_{1}-\rho_{2}\right)\left(\frac{1}{2}+\frac{x}{L}\right)^{p_{x}}\left(\frac{1}{2}+\frac{z}{h}\right)^{p_{z}}+\rho_{2}
\end{aligned}
$$

\subsection{Constitutive Equations}

The axial and transverse displacements of a beam by using the present shear and normal deformation theory including both shear deformation and thickness stretching effects are given by

$$
\begin{aligned}
& U(x, z, t)=u(x, t)-z \frac{\partial w_{b}(x, t)}{\partial x}-\frac{4 z^{3}}{3 h^{2}} \frac{\partial w_{s}(x, t)}{\partial x} \\
& =u(x, t)-z w_{b}^{\prime}(x, t)-f(z) w_{s}^{\prime}(x, t) \\
& W(x, z, t)=w_{b}(x, t)+w_{s}(x, t)+\left(1-\frac{4 z^{2}}{h^{2}}\right) w_{z}(x, t) \\
& \quad=w_{b}(x, t)+w_{s}(x, t)+g(z) w_{z}(x, t)
\end{aligned}
$$

where $u, w_{b}, w_{s}$ and $w_{z}$ are four variables to be determined.

The only nonzero strains associated with the displacement field given in Eq. (5) can be written by:

$$
\begin{aligned}
& \varepsilon_{x}=\frac{\partial U}{\partial x}=u^{\prime}-z w_{b}^{\prime \prime}-f(z) w_{s}^{\prime \prime} \\
& \varepsilon_{z}=\frac{\partial W}{\partial z}=g^{\prime}(z) w_{z}
\end{aligned}
$$


Karamanlı / Anadolu Univ. J. of Sci. and Technology A-Appl. Sci. and Eng. 19 (2) - 2018

$$
\gamma_{x z}=\frac{\partial W}{\partial x}+\frac{\partial U}{\partial z}=g(z)\left(w_{s}^{\prime}+w_{z}^{\prime}\right)
$$

The following linear elastic constitutive equation can be written by using the related stresses and strains based on the assumption of constant Poisson's ratio for the sake of simplicity:

$$
\left[\begin{array}{c}
\sigma_{x} \\
\sigma_{z} \\
\sigma_{x z}
\end{array}\right]=\frac{E(x, z)}{1-v^{2}}\left[\begin{array}{ccc}
1 & v & 0 \\
v & 1 & 0 \\
0 & 0 & \frac{1-v}{2}
\end{array}\right]\left[\begin{array}{c}
\varepsilon_{x} \\
\varepsilon_{z} \\
\gamma_{x z}
\end{array}\right]
$$

\subsection{Variational Formulation}

The strain energy of the beam including the energy associated with the shearing strain can be written as,

$$
U=\frac{1}{2} \int_{V}\left(\sigma_{x} \varepsilon_{x}+\sigma_{z} \varepsilon_{z}+\sigma_{x z} \gamma_{x z}\right) d V
$$

where $V$ is the volume of the beam. Substituting Eqs. (6) and (7) into Eq. (8), the strain energy can be obtained as the form of:

$$
u=\frac{1}{2} \int_{V} \frac{E(x, z)}{1-v^{2}}\left[\varepsilon_{x} \varepsilon_{x}+2 v \varepsilon_{x} \varepsilon_{z}+\varepsilon_{z} \varepsilon_{z}+\frac{1-v}{2} \gamma_{x z} \gamma_{x z}\right] d V
$$

Where

$$
\begin{aligned}
\varepsilon_{x} \varepsilon_{x}= & \left(\frac{\partial u}{\partial x}\right)^{2}+z^{2}\left(\frac{\partial^{2} w_{b}}{\partial x^{2}}\right)^{2}+f^{2}\left(\frac{\partial^{2} w_{s}}{\partial x^{2}}\right)^{2}-2 z\left(\frac{\partial u}{\partial x}\right)\left(\frac{\partial^{2} w_{b}}{\partial x^{2}}\right)-2 f\left(\frac{\partial u}{\partial x}\right)\left(\frac{\partial^{2} w_{s}}{\partial x^{2}}\right) \\
& +2 f z\left(\frac{\partial^{2} w_{b}}{\partial x^{2}}\right)\left(\frac{\partial^{2} w_{s}}{\partial x^{2}}\right) \\
\varepsilon_{x} \varepsilon_{z}= & \left(\frac{d g}{d z}\right)\left(\frac{\partial u}{\partial x}\right) w_{z}-\left(\frac{d g}{d z}\right) z\left(\frac{\partial^{2} w_{b}}{\partial x^{2}}\right) w_{z}-\left(\frac{d g}{d z}\right) f\left(\frac{\partial^{2} w_{s}}{\partial x^{2}}\right) w_{z} \\
\varepsilon_{z} \varepsilon_{z}= & \left(\frac{d g}{d z}\right)^{2} w_{z}^{2} \\
\gamma_{x z} \gamma_{x z}= & g^{2}\left(\frac{\partial w_{s}}{\partial x}\right)^{2}+g^{2}\left(\frac{\partial w_{z}}{\partial x}\right)^{2}+2 g^{2}\left(\frac{\partial w_{s}}{\partial x}\right)\left(\frac{\partial w_{z}}{\partial x}\right)
\end{aligned}
$$

It is useful to introduce the stiffness coefficients as follows:

$$
\begin{gathered}
\left(A, B, B_{s}, D, D_{s}, H, Z\right)=b \int_{-h / 2}^{+h / 2} \frac{\left(E_{1}-E_{2}\right)}{1-v^{2}}\left(\frac{1}{2}+\frac{z}{h}\right)^{p_{z}}\left(1, z, f, z^{2}, f z, f^{2}, g^{\prime 2}\right) d z \\
\left(A_{1}, B_{1}, B_{s 1}, D_{1}, D_{s 1}, H_{1}, Z_{1}\right)=b \int_{-h / 2}^{+h / 2} \frac{E_{2}}{1-v^{2}}\left(1, z, f, z^{2}, f z, f^{2}, g^{\prime 2}\right) d z \\
A_{s}=b \int_{-h / 2}^{+h / 2} \frac{\left(E_{1}-E_{2}\right)}{2(1+v)}\left(\frac{1}{2}+\frac{z}{h}\right)^{p_{z}} g^{2} d z \\
A_{s 1}=b \int_{-h / 2}^{+h / 2} \frac{E_{2}}{2(1+v)} g^{2} d z
\end{gathered}
$$




$$
\begin{aligned}
& \left(X, Y, Y_{S}\right)=b \int_{-h / 2}^{+h / 2} \frac{\left(E_{1}-E_{2}\right) v}{1-v^{2}}\left(\frac{1}{2}+\frac{z}{h}\right)^{p_{z}} g^{\prime}(1, z, f) d z \\
& \left(X_{1}, Y_{1}, Y_{S 1}\right)=b \int_{-h / 2}^{+h / 2} \frac{E_{2} v}{1-v^{2}} g^{\prime}(1, z, f) d z
\end{aligned}
$$

Using Eqs. 9 to 12, the strain energy can be written in the form of:

$$
\begin{gathered}
U=\frac{1}{2} \int_{-L / 2}^{L / 2}\left[\left\{A\left(\frac{1}{2}+\frac{x}{L}\right)^{p_{x}}+A_{1}\right\}\left(\frac{\partial u}{\partial x}\right)^{2}+\left\{D\left(\frac{1}{2}+\frac{x}{L}\right)^{p_{x}}+D_{1}\right\}\left(\frac{\partial^{2} w_{b}}{\partial x^{2}}\right)^{2}+\right. \\
\left\{H\left(\frac{1}{2}+\frac{x}{L}\right)^{p_{x}}+H_{1}\right\}\left(\frac{\partial^{2} w_{s}}{\partial x^{2}}\right)^{2}+2\left\{D_{s}\left(\frac{1}{2}+\frac{x}{L}\right)^{p_{x}}+D_{s 1}\right\}\left(\frac{\partial^{2} w_{b}}{\partial x^{2}}\right)\left(\frac{\partial^{2} w_{s}}{\partial x^{2}}\right)- \\
2\left\{B\left(\frac{1}{2}+\frac{x}{L}\right)^{p_{x}}+B_{1}\right\}\left(\frac{\partial u}{\partial x}\right)\left(\frac{\partial^{2} w_{b}}{\partial x^{2}}\right)-2\left\{B_{s}\left(\frac{1}{2}+\frac{x}{L}\right)^{p_{x}}+B_{s 1}\right\}\left(\frac{\partial u}{\partial x}\right)\left(\frac{\partial^{2} w_{s}}{\partial x^{2}}\right)+ \\
2\left\{X\left(\frac{1}{2}+\frac{x}{L}\right)^{p_{x}}+X_{1}\right\}\left(\frac{\partial u}{\partial x}\right) w_{z}-2\left\{Y\left(\frac{1}{2}+\frac{x}{L}\right)^{p_{x}}+Y_{1}\right\}\left(\frac{\partial^{2} w_{b}}{\partial x^{2}}\right) w_{z}- \\
2\left\{Y_{s}\left(\frac{1}{2}+\frac{x}{L}\right)^{p_{x}}+Y_{s 1}\right\}\left(\frac{\partial^{2} w_{s}}{\partial x^{2}}\right)^{p_{z}}+\left\{Z\left(\frac{1}{2}+\frac{x}{L}\right)^{p_{x}}+Z_{1}\right\} w_{z}^{2}+ \\
\left.\left\{A_{s}\left(\frac{1}{2}+\frac{x}{L}\right)^{p_{x}}+A_{s 1}\right\}\left\{\left(\frac{\partial w_{s}}{\partial x}\right)^{2}+\left(\frac{\partial w_{z}}{\partial x}\right)^{2}+2\left(\frac{\partial w_{s}}{\partial x}\right)\left(\frac{\partial w_{z}}{\partial x}\right)\right\}\right] d x
\end{gathered}
$$

The potential energy of the axial $N_{0}$ and distributed $\mathrm{q}(\mathrm{x})$ loads is given by

$$
V=-\frac{1}{2} \int_{-L / 2}^{L / 2} N_{0}\left\{\left(\frac{\partial w_{b}}{\partial x}\right)^{2}+2 \frac{\partial w_{b}}{\partial x} \frac{\partial w_{s}}{\partial x}+\left(\frac{\partial w_{s}}{\partial x}\right)^{2}\right\} d x-\int_{0}^{L} q\left(w_{b}+w_{s}\right) d x
$$

The kinetic energy of present four-unknown shear and normal deformable beam theory can be obtained by using similar procedure as follows

$$
\begin{aligned}
K=\frac{1}{2} \int_{-L / 2}^{L / 2}\left[I_{0}\right. & \left.\left(\frac{1}{2}+\frac{x}{L}\right)^{p_{x}}+I_{00}\right\}\left\{\left(\frac{\partial u}{\partial t}\right)^{2}+\left(\frac{\partial w_{b}}{\partial t}\right)^{2}+\left(\frac{\partial w_{s}}{\partial t}\right)^{2}+2\left(\frac{\partial w_{b}}{\partial t}\right)\left(\frac{\partial w_{s}}{\partial t}\right)\right\} \\
& -2\left\{I_{1}\left(\frac{1}{2}+\frac{x}{L}\right)^{p_{x}}+I_{11}\right\} \frac{\partial u}{\partial t} \frac{\partial^{2} w_{b}}{\partial x \partial t}+\left\{I_{2}\left(\frac{1}{2}+\frac{x}{L}\right)^{p_{x}}+I_{22}\right\}\left(\frac{\partial^{2} w_{b}}{\partial x \partial t}\right)^{2} \\
& -2\left\{J_{1}\left(\frac{1}{2}+\frac{x}{L}\right)^{p_{x}}+J_{11}\right\} \frac{\partial u}{\partial t} \frac{\partial^{2} w_{s}}{\partial x \partial t} \\
& +2\left\{J_{2}\left(\frac{1}{2}+\frac{x}{L}\right)^{p_{x}}+J_{22}\right\}\left\{\left(\frac{\partial w_{b}}{\partial t}\right)\left(\frac{\partial w_{z}}{\partial t}\right)+\left(\frac{\partial w_{s}}{\partial t}\right)\left(\frac{\partial w_{z}}{\partial t}\right)\right\} \\
& +2\left\{J_{3}\left(\frac{1}{2}+\frac{x}{L}\right)^{p_{x}}+J_{33}\right\} \frac{\partial^{2} w_{b}}{\partial x \partial t} \frac{\partial^{2} w_{s}}{\partial x \partial t}+\left\{K_{1}\left(\frac{1}{2}+\frac{x}{L}\right)^{p_{x}}+K_{11}\right\}\left(\frac{\partial^{2} w_{s}}{\partial x \partial t}\right)^{2} \\
& \left.+\left\{K_{2}\left(\frac{1}{2}+\frac{x}{L}\right)^{p_{x}}+K_{22}\right\}\left(\frac{\partial w_{z}}{\partial t}\right)^{2}\right] d x
\end{aligned}
$$

Here $\mathrm{t}$ is the time, and the inertial coefficients can be presented as 


$$
\begin{aligned}
& \left(I_{0}, I_{1}, I_{2}, J_{1}, J_{2}, J_{3}, K_{1}, K_{2}\right)=b \int_{-\frac{h}{2}}^{+\frac{h}{2}}\left(\rho_{1}-\rho_{2}\right)\left(\frac{1}{2}+\frac{z}{h}\right)^{p_{z}}\left(1, z, z^{2}, f, g, f z, f^{2}, g^{2}\right) d z \\
& \left(I_{00}, I_{11}, I_{22}, J_{11}, J_{22}, J_{33}, K_{11}, K_{21}\right)=b \int_{-h / 2}^{+h / 2} \rho_{2}\left(1, z, z^{2}, f, g, f z, f^{2}, g^{2}\right) d z
\end{aligned}
$$

The total potential energy (П) can be obtained by using Eqs. (12), (13) and (14),

$$
\begin{aligned}
& \Pi=\mathcal{U}+V-K \\
& \Pi=\frac{1}{2} \int_{-L / 2}^{L / 2}\left[\left\{A\left(\frac{1}{2}+\frac{x}{L}\right)^{p_{x}}+A_{1}\right\}\left(\frac{\partial u}{\partial x}\right)^{2}+\left\{D\left(\frac{1}{2}+\frac{x}{L}\right)^{p_{x}}+D_{1}\right\}\left(\frac{\partial^{2} w_{b}}{\partial x^{2}}\right)^{2}\right. \\
& +\left\{H\left(\frac{1}{2}+\frac{x}{L}\right)^{p_{x}}+H_{1}\right\}\left(\frac{d^{2} w_{s}}{d x^{2}}\right)^{2}+2\left\{D_{s}\left(\frac{1}{2}+\frac{x}{L}\right)^{p_{x}}+D_{s 1}\right\}\left(\frac{\partial^{2} w_{b}}{\partial x^{2}}\right)\left(\frac{\partial^{2} w_{s}}{\partial x^{2}}\right) \\
& -2\left\{B\left(\frac{1}{2}+\frac{x}{L}\right)^{p_{x}}+B_{1}\right\}\left(\frac{\partial u}{\partial x}\right)\left(\frac{\partial^{2} w_{b}}{\partial x^{2}}\right)-2\left\{B_{s}\left(\frac{1}{2}+\frac{x}{L}\right)^{p_{x}}+B_{s 1}\right\}\left(\frac{\partial u}{\partial x}\right)\left(\frac{\partial^{2} w_{s}}{\partial x^{2}}\right) \\
& +2\left\{X\left(\frac{1}{2}+\frac{x}{L}\right)^{p_{x}}+X_{1}\right\}\left(\frac{\partial u}{\partial x}\right) w_{z}-2\left\{Y\left(\frac{1}{2}+\frac{x}{L}\right)^{p_{x}}+Y_{1}\right\}\left(\frac{\partial^{2} w_{b}}{\partial x^{2}}\right) w_{z} \\
& -2\left\{Y_{s}\left(\frac{1}{2}+\frac{x}{L}\right)^{p_{x}}+Y_{s 1}\right\}\left(\frac{\partial^{2} w_{s}}{\partial x^{2}}\right) w_{z}+\left\{Z\left(\frac{1}{2}+\frac{x}{L}\right)^{p_{x}}+Z_{1}\right\} w_{z}^{2} \\
& +\left\{A_{s}\left(\frac{1}{2}+\frac{x}{L}\right)^{p_{x}}+A_{s 1}\right\}\left\{\left(\frac{\partial w_{s}}{\partial x}\right)^{2}+\left(\frac{\partial w_{z}}{\partial x}\right)^{2}+2\left(\frac{\partial w_{s}}{\partial x}\right)\left(\frac{\partial w_{z}}{\partial x}\right)\right\} \\
& -\left\{I_{0}\left(\frac{1}{2}+\frac{x}{L}\right)^{p_{x}}+I_{00}\right\}\left\{\left(\frac{\partial u}{\partial t}\right)^{2}+\left(\frac{\partial w_{b}}{\partial t}\right)^{2}+\left(\frac{\partial w_{s}}{\partial t}\right)^{2}+2\left(\frac{\partial w_{b}}{\partial t}\right)\left(\frac{\partial w_{s}}{\partial t}\right)\right\} \\
& +2\left\{I_{1}\left(\frac{1}{2}+\frac{x}{L}\right)^{p_{x}}+I_{11}\right\} \frac{\partial u}{\partial t} \frac{\partial^{2} w_{b}}{\partial x \partial t}-\left\{I_{2}\left(\frac{1}{2}+\frac{x}{L}\right)^{p_{x}}+I_{22}\right\}\left(\frac{\partial^{2} w_{b}}{\partial x \partial t}\right)^{2} \\
& +2\left\{J_{1}\left(\frac{1}{2}+\frac{x}{L}\right)^{p_{x}}+J_{11}\right\} \frac{\partial u}{\partial t} \frac{\partial^{2} w_{s}}{\partial x \partial t}-2\left\{J_{2}\left(\frac{1}{2}+\frac{x}{L}\right)^{p_{x}}+J_{22}\right\}\left\{\left(\frac{\partial w_{b}}{\partial t}\right)\left(\frac{\partial w_{z}}{\partial t}\right)+\left(\frac{\partial w_{s}}{\partial t}\right)\left(\frac{\partial w_{z}}{\partial t}\right)\right\} \\
& -2\left\{J_{3}\left(\frac{1}{2}+\frac{x}{L}\right)^{p_{x}}+J_{33}\right\} \frac{\partial^{2} w_{b}}{\partial x \partial t} \frac{\partial^{2} w_{s}}{\partial x \partial t}-\left\{K_{1}\left(\frac{1}{2}+\frac{x}{L}\right)^{p_{x}}+K_{11}\right\}\left(\frac{\partial^{2} w_{s}}{\partial x \partial t}\right)^{2} \\
& \left.-\left\{K_{2}\left(\frac{1}{2}+\frac{x}{L}\right)^{p_{x}}+K_{22}\right\}\left(\frac{\partial w_{z}}{\partial t}\right)^{2}-N_{0}\left\{\left(\frac{\partial w_{b}}{\partial x}\right)^{2}+2 \frac{\partial w_{b}}{\partial x} \frac{\partial w_{s}}{\partial x}+\left(\frac{\partial w_{s}}{\partial x}\right)^{2}\right\}-2 q\left(w_{b}+w_{s}\right)\right] d x
\end{aligned}
$$

\subsection{Solution Procedure}

It is known that Hamilton's principle can be expressed as Lagrange equations when the functions of infinite dimensions can be expressed in terms of generalized coordinates. Therefore, the displacement functions $u(\mathrm{x}), w_{b}(x), w_{s}(x)$ and $w_{z}(x)$ are presented by the following polynomial series which are satisfy the kinematic boundary conditions given in Table 1 ,

$$
\begin{aligned}
u(x) & =\sum_{j=1}^{m} A_{j} e^{i \omega t} \theta_{j}(x), & \theta_{j}(x) & =\left(x+\frac{L}{2}\right)^{p_{u}}\left(x-\frac{L}{2}\right)^{q_{u}} x^{j-1} \\
w_{b}(x) & =\sum_{j=1}^{m} B_{j} e^{i \omega t} \varphi_{j}(x), & \varphi_{j}(x) & =\left(x+\frac{L}{2}\right)^{p_{w_{b}}}\left(x-\frac{L}{2}\right)^{q_{w_{b}}} x^{j-1}
\end{aligned}
$$


Karamanlı / Anadolu Univ. J. of Sci. and Technology A-Appl. Sci. and Eng. 19 (2) - 2018

$$
\begin{array}{ll}
w_{s}(x)=\sum_{j=1}^{m} C_{j} e^{i \omega t} \zeta_{j}(x), & \zeta_{j}(x)=\left(x+\frac{L}{2}\right)^{p_{w_{s}}}\left(x-\frac{L}{2}\right)^{q_{w_{s}}} x^{j-1} \\
w_{z}(x)=\sum_{j=1}^{m} D_{j} e^{i \omega t} \psi_{j}(x), & \psi_{j}(x)=\left(x+\frac{L}{2}\right)^{p_{w_{z}}}\left(x-\frac{L}{2}\right)^{q_{w_{z}}} x^{j-1}
\end{array}
$$

where $A_{j}, B_{j}, C_{j}$ and $D_{j}$ are unknown values to be determined, $\omega$ is the natural frequency of the beam, $i=\sqrt{-1}$ is the complex number, $\theta_{j}(x), \varphi_{j}(x), \zeta_{j}(x)$ and $\psi_{j}(x)$ are the shape functions which are proposed for the boundary conditions (BCs) to be studied within this paper, $p_{\xi}$ and $q_{\xi}(\xi=$ $u, w_{b}, w_{s}, w_{z}$ ) are the boundary exponents of the auxiliary functions related with the boundary conditions given in Table 2. It has to be mentioned that the shape functions which do not satisfy the boundary conditions may cause slow convergence rates and numerical instabilities.

Table 1. Kinematic boundary conditions used for the numerical computations.

\begin{tabular}{ccc}
\hline $\mathbf{B C}$ & $\mathbf{x}=\mathbf{- \mathbf { L } / 2}$ & $\mathbf{x}=\mathbf{L} / \mathbf{2}$ \\
\hline $\mathrm{SS}$ & $u=0, w_{b}=0, w_{S}=0, w_{z}=0$ & $w_{b}=0, w_{S}=0, w_{z}=0$ \\
\hline $\mathrm{CS}$ & $u=0, w_{b}=0, w_{S}=0, w_{z}=0, w_{b}{ }^{\prime}=0, w_{S}{ }^{\prime}=0$ & $w_{b}=0, w_{S}=0, w_{z}=0$ \\
\hline $\mathrm{CC}$ & $u=0, w_{b}=0, w_{S}=0, w_{z}=0, w_{b}{ }^{\prime}=0, w_{S}{ }^{\prime}=0$ & $u=0, w_{b}=0, w_{S}=0, w_{z}=0, w_{b}{ }^{\prime}=0, w_{S}{ }^{\prime}=0$ \\
\hline $\mathrm{CF}$ & $u=0, w_{b}=0, w_{S}=0, w_{z}=0, w_{b}{ }^{\prime}=0, w_{S}{ }^{\prime}=0$ & \\
\hline
\end{tabular}

Table 2. Boundary exponents for various boundary conditions.

\begin{tabular}{ccccccccc}
\hline & \multicolumn{9}{c}{ Left end } & \multicolumn{5}{c}{ Right end } \\
\cline { 2 - 10 } & $\boldsymbol{p}_{\boldsymbol{u}}$ & $\boldsymbol{p}_{\boldsymbol{w}_{\boldsymbol{b}}}$ & $\boldsymbol{p}_{\boldsymbol{w}_{\boldsymbol{s}}}$ & $\boldsymbol{p}_{\boldsymbol{w}_{\boldsymbol{z}}}$ & $\boldsymbol{q}_{\boldsymbol{u}}$ & $\boldsymbol{q}_{\boldsymbol{w}_{\boldsymbol{b}}}$ & $\boldsymbol{q}_{\boldsymbol{w}_{\boldsymbol{s}}}$ & $\boldsymbol{q}_{\boldsymbol{w}_{\boldsymbol{z}}}$ \\
\hline $\mathrm{SS}$ & 1 & 1 & 1 & 1 & 0 & 1 & 1 & 1 \\
\hline $\mathrm{CS}$ & 1 & 2 & 2 & 1 & 0 & 1 & 1 & 1 \\
\hline $\mathrm{CC}$ & 1 & 2 & 2 & 1 & 1 & 2 & 2 & 1 \\
\hline $\mathrm{CF}$ & 1 & 2 & 2 & 1 & 0 & 0 & 0 & 0 \\
\hline
\end{tabular}

The governing equations of motion for free vibration analysis can be obtained by substituting Eq. (16) into Eq. (15) and using Lagrange equations

$$
\frac{\partial \Pi}{\partial q_{j}}-\frac{\partial}{\partial t}\left(\frac{\partial \Pi}{\partial \dot{q}_{j}}\right)=0
$$

with $q_{j}$ representing the values of $\left(A_{j}, B_{j}, C_{j}\right.$ and $\left.D_{j}\right)$, that leads to

$$
\left(\left[\begin{array}{llll}
{\left[K_{11}\right]} & {\left[K_{12}\right]} & {\left[K_{13}\right]} & {\left[K_{14}\right]} \\
{\left[K_{12}\right]^{T}} & {\left[K_{22}\right]} & {\left[K_{23}\right]} & {\left[K_{24}\right]} \\
{\left[K_{13}\right]^{T}} & {\left[K_{23}\right]^{T}} & {\left[K_{33}\right]} & {\left[K_{34}\right]} \\
{\left[K_{14}\right]^{T}} & {\left[K_{24}\right]^{T}} & {\left[K_{34}\right]^{T}} & {\left[K_{44}\right]}
\end{array}\right]-\omega^{2}\left[\begin{array}{llll}
{\left[M_{11}\right]} & {\left[M_{12}\right]} & {\left[M_{13}\right]} & {\left[M_{14}\right]} \\
{\left[M_{12}\right]^{T}} & {\left[M_{22}\right]} & {\left[M_{23}\right]} & {\left[M_{24}\right]} \\
{\left[M_{13}\right]^{T}} & {\left[M_{23}\right]^{T}} & {\left[M_{33}\right]} & {\left[M_{34}\right]} \\
{\left[M_{14}\right]^{T}} & {\left[M_{24}\right]^{T}} & {\left[M_{34}\right]^{T}} & {\left[M_{44}\right]}
\end{array}\right]\right)\left\{\begin{array}{l}
\{A\} \\
\{B\} \\
\{C\} \\
\{D\}
\end{array}\right\}=\left\{\begin{array}{l}
\{0\} \\
\{0\} \\
\{0\}
\end{array}\right\}
$$

where $\left[K_{k l}\right]$ are the stiffness matrices and $\left[M_{k l}\right]$ are the mass matrices. It should be noted that the stiffness and mass matrices are symmetric and in size $\mathrm{mxm}$.

The components of the stiffness and mass matrices are given by: 
Karamanl / Anadolu Univ. J. of Sci. and Technology A-Appl. Sci. and Eng. 19 (2)-2018

$$
\begin{aligned}
& K_{11}(i, j)=\int_{-L / 2}^{L / 2}\left[A\left(\frac{1}{2}+\frac{x}{L}\right)^{p_{x}}+A_{1}\right] \theta_{i, x} \theta_{j, x} d x \\
& K_{12}(i, j)=-\int_{\substack{L / 2 \\
L / 2}}^{L / 2}\left[B\left(\frac{1}{2}+\frac{x}{L}\right)^{p_{x}}+B_{1}\right] \theta_{i, x} \varphi_{j, x x} d x \\
& K_{13}(i, j)=-\int_{-L / 2}^{L / 2}\left[B_{s}\left(\frac{1}{2}+\frac{x}{L}\right)^{p_{x}}+B_{s 1}\right] \theta_{i, x} \zeta_{j, x x} d x \\
& K_{14}(i, j)=\int_{-L / 2}^{L / 2}\left[X\left(\frac{1}{2}+\frac{x}{L}\right)^{p_{x}}+X_{1}\right] \theta_{i, x} \psi_{j} d x \\
& K_{22}(i, j)=\int_{-L / 2}^{L / 2}\left[D\left(\frac{1}{2}+\frac{x}{L}\right)^{p_{x}}+D_{1}\right] \varphi_{i, x x} \varphi_{j, x x} d x-N_{0} \int_{-L / 2}^{L / 2} \varphi_{i, x} \varphi_{j, x} d x \\
& K_{23}(i, j)=\int_{-L / 2}^{L / 2}\left[D_{s}\left(\frac{1}{2}+\frac{x}{L}\right)^{p_{x}}+D_{s 1}\right] \varphi_{i, x x} \zeta_{j, x x} d x-N_{0} \int_{-L / 2}^{L / 2} \varphi_{i, x} \zeta_{j, x} d x \\
& K_{24}(i, j)=-\int_{-L / 2}^{L / 2}\left[Y\left(\frac{1}{2}+\frac{x}{L}\right)^{p_{x}}+Y_{1}\right] \varphi_{i, x x} \psi_{j} d x \\
& K_{33}(i, j)=\int_{-L / 2}^{L / 2}\left[H\left(\frac{1}{2}+\frac{x}{L}\right)^{p_{x}}+H_{1}\right] \zeta_{i, x x} \zeta_{j, x x} d x+\int_{-L / 2}^{L / 2}\left[A_{s}\left(\frac{1}{2}+\frac{x}{L}\right)^{p_{x}}+A_{s 1}\right] \zeta_{i, x} \zeta_{j, x} d x \\
& -N_{0} \int_{-L / 2}^{L / 2} \zeta_{i, x} \zeta_{j, x} d x-\int_{-L / 2}^{L / 2} q(x) \zeta_{i} \zeta_{j} d x \\
& K_{34}(i, j)=-\int_{\substack{L / 2 \\
L / 2}}^{L / 2}\left[Y_{s}\left(\frac{1}{2}+\frac{x}{L}\right)^{p_{x}}+Y_{s 1}\right] \zeta_{i, x x} \psi_{j} d x+\int_{\substack{L / 2 \\
L / 2}}^{L / 2}\left[A_{s}\left(\frac{1}{2}+\frac{x}{L}\right)^{p_{x}}+A_{s 1}\right] \zeta_{i, x} \psi_{j, x} d x \\
& K_{44}(i, j)=\int_{-L / 2}^{L / 2}\left[Z\left(\frac{1}{2}+\frac{x}{L}\right)^{p_{x}}+Z_{1}\right] \psi_{i} \psi_{j} d x+\int_{-L / 2}^{L / 2}\left[A_{s}\left(\frac{1}{2}+\frac{x}{L}\right)^{p_{x}}+A_{s 1}\right] \psi_{i, x} \psi_{j, x} d x \\
& M_{11}(i, j)=\int_{-L / 2}^{L / 2}\left[I_{0}\left(\frac{1}{2}+\frac{x}{L}\right)^{p_{x}}+I_{00}\right] \theta_{i} \theta_{j} d x \\
& M_{12}(i, j)=-\int_{-L / 2}^{L / 2}\left[I_{1}\left(\frac{1}{2}+\frac{x}{L}\right)^{p_{x}}+I_{11}\right] \theta_{i} \varphi_{j, x} d x \text {, } \\
& M_{13}(i, j)=-\int_{-L / 2}^{L / 2}\left[J_{1}\left(\frac{1}{2}+\frac{x}{L}\right)^{p_{x}}+J_{11}\right] \theta_{i} \zeta_{j, x} d x
\end{aligned}
$$




$$
\begin{gathered}
M_{22}(i, j)=\int_{-L / 2}^{L / 2}\left[I_{0}\left(\frac{1}{2}+\frac{x}{L}\right)^{p_{x}}+I_{00}\right] \varphi_{i} \varphi_{j} d x+\int_{-L / 2}^{L / 2}\left[I_{2}\left(\frac{1}{2}+\frac{x}{L}\right)^{p_{x}}+I_{22}\right] \varphi_{i, x} \varphi_{j, x} d x \\
M_{23}(i, j)=\int_{-L / 2}^{L / 2}\left[I_{0}\left(\frac{1}{2}+\frac{x}{L}\right)^{p_{x}}+I_{00}\right] \varphi_{i} \zeta_{j} d x+\int_{-L / 2}^{p_{x}}\left[J_{3}\left(\frac{1}{2}+\frac{x}{L}\right)^{p_{x}}+J_{33}\right] \varphi_{i, x} \zeta_{j, x} d x \\
M_{24}(i, j)=\int_{-L / 2}^{L / 2}\left[J_{2}\left(\frac{1}{2}+\frac{x}{L}\right)^{p_{x}}+J_{22}\right] \varphi_{i} \psi_{j} d x \\
M_{33}(i, j)=\int_{-L / 2}^{L / 2}\left[I_{0}\left(\frac{1}{2}+\frac{x}{L}\right)^{p_{x}}+I_{00}\right] \zeta_{i} \zeta_{j} d x+\int_{-L / 2}^{L / 2}\left[K_{1}\left(\frac{1}{2}+\frac{x}{L}\right)^{p_{x}}+K_{11}\right] \zeta_{i, x} \zeta_{j, x} d x \\
M_{34}(i, j)=\int_{-L / 2}^{L / 2}\left[J_{2}\left(\frac{1}{2}+\frac{x}{L}\right)^{p_{x}}+J_{22}\right] \zeta_{i} \psi_{j} d x \\
M_{44}(i, j)=\int_{-L / 2}^{L / 2}\left[K_{2}\left(\frac{1}{2}+\frac{x}{L}\right)^{p_{x}}+K_{22}\right] \psi_{i} \psi_{j} d x \quad i, j=1,2,3, \ldots, m
\end{gathered}
$$

The free vibration and buckling behavior of the two directional FGBs can be investigated by using Eqs. (18) and (19).

\section{NUMERICAL RESULTS}

In this section a number of numerical examples are presented to discuss the effects of gradient indexes (or material composition), aspect ratios and boundary conditions on the critical buckling loads and natural frequencies of the two directional FGBs using a quasi-3D shear deformation theory. It is assumed that the Poisson's ratio is constant and the material properties vary along both longitudinal and thickness directions according to the power-law distribution. Two different aspect ratios $(\mathrm{L} / \mathrm{h}) 5$ and 20 are considered with arbitrary boundary conditions, namely simply supported-simply supported (SS), clamped-simply supported (CS), clamped-clamped (CC) and clamped-free (CF).

The material properties of the two constitutes are given as

Ceramic $\left(\mathrm{Al}_{2} \mathrm{O}_{3}\right) \quad: E_{1}=380 \mathrm{GPa}, v_{1}=0.3$ and $\rho_{1}=3960 \mathrm{~kg} / \mathrm{m}^{3}$

Metal (Aluminium) $: E_{2}=70 G P a, v_{2}=0.3$ and $\rho_{2}=2702 \mathrm{~kg} / \mathrm{m}^{3}$

The following non-dimensional quantities are used for the representation of the results;

The dimensionless buckling load $\left(\bar{N}_{c r}\right)$

$$
\bar{N}_{c r}=\frac{12 N_{c r} L^{2}}{E_{2} b h^{3}}
$$

The dimensionless frequency $(\lambda)$

$$
\lambda=\frac{\omega L^{2}}{h} \sqrt{\frac{\rho_{2}}{E_{2}}}
$$


Karamanlı / Anadolu Univ. J. of Sci. and Technology A-Appl. Sci. and Eng. 19 (2) - 2018

Table 3. Verification and convergence studies, dimensionless fundamental frequency $(\lambda)$ of homogeneous beams with respect to various boundary conditions and aspect ratio change.

\begin{tabular}{|c|c|c|c|c|c|}
\hline \multirow{2}{*}{$\mathbf{L} / \mathbf{h}$} & \multirow{2}{*}{\multicolumn{2}{|c|}{ Reference }} & \multicolumn{3}{|c|}{ Boundary Condition } \\
\hline & & & SS & $\mathrm{CC}$ & $\mathbf{C F}$ \\
\hline \multirow{10}{*}{5} & \multicolumn{2}{|c|}{ HBT [23] } & 5.1528 & 10.0726 & 1.8953 \\
\hline & \multicolumn{2}{|c|}{ Quasi-3D [24] } & 5.1618 & 10.1851 & 1.9055 \\
\hline & \multicolumn{2}{|c|}{ Quasi-3D [25] } & 5.1620 & 10.1790 & 1.9053 \\
\hline & \multirow{7}{*}{ Present } & 2 terms & 5.7158 & 10.5992 & 1.9477 \\
\hline & & 4 terms & 5.1631 & 10.3276 & 1.9172 \\
\hline & & 6 terms & 5.1616 & 10.2488 & 1.9107 \\
\hline & & 8 terms & 5.1616 & 10.2064 & 1.9078 \\
\hline & & 10 terms & 5.1616 & 10.1835 & 1.9061 \\
\hline & & 12 terms & 5.1616 & 10.1759 & 1.9053 \\
\hline & & 14 terms & 5.1616 & 10.1748 & 1.9051 \\
\hline \multirow{10}{*}{20} & \multicolumn{2}{|c|}{ HBT [23] } & 5.4603 & 12.2243 & 1.9496 \\
\hline & \multirow{2}{*}{\multicolumn{2}{|c|}{$\begin{array}{l}\text { Quasi-3D [24] } \\
\text { Quasi-3D [25] }\end{array}$}} & 5.4610 & 12.2660 & 1.9527 \\
\hline & & & 5.4611 & 12.2756 & 1.9530 \\
\hline & \multirow{7}{*}{ Present } & 2 terms & 6.1034 & 12.7736 & 1.9959 \\
\hline & & 4 terms & 5.4627 & 12.3896 & 1.9647 \\
\hline & & 6 terms & 5.4610 & 12.3218 & 1.9577 \\
\hline & & 8 terms & 5.4610 & 12.2930 & 1.9549 \\
\hline & & 10 terms & 5.4610 & 12.2794 & 1.9537 \\
\hline & & 12 terms & 5.4610 & 12.2721 & 1.9531 \\
\hline & & 14 terms & 5.4610 & 12.2676 & 1.9527 \\
\hline
\end{tabular}

Firstly, the numerical computations are performed for the convergence analysis to make comparison studies along with the solutions from previous studies [18-24-29]. The convergence and verification studies are carried out by employing different number of terms in the displacement functions $(\mathrm{m}=2,4,6$, $8,10,12$ and 14) and different aspect ratios ( $\mathrm{L} / \mathrm{h}=5$ and 20$)$. The computed results are presented in terms of dimensionless fundamental frequencies and dimensionless critical buckling loads of a homogenous beam considering various boundary conditions, namely SS, CC and CF. The present results based on the dimensionless fundamental frequencies of the homogenous beams agree well with those from the previous studies [18-24-29]. It can be seen that for the free vibration analysis of SS beams, the responses converge quickly, when the number of terms in polynomial expansion is set to 6 as given in Table 3 . However, the agreed results are obtained for CC and CF boundary conditions by employing 10 terms in polynomial expansion as it is seen in Table 3 . It is clear that the dimensionless fundamental frequencies obtained based on the Quasi-3D theories are a bit higher than the ones based on the HBT. For the sake of accuracy, 12 terms in the polynomial expansion is employed for the extensive free vibration analysis of two directional FGBs.

Table 4. Verification and convergence studies, dimensionless critical buckling loads $\left(\bar{N}_{c r}\right)$ of homogeneous beams with respect to various boundary conditions and aspect ratio change.

\begin{tabular}{|c|c|c|c|c|c|}
\hline \multirow{2}{*}{$\mathbf{L} / \mathbf{h}$} & \multirow{2}{*}{\multicolumn{2}{|c|}{ Reference }} & \multicolumn{3}{|c|}{ Boundary Condition } \\
\hline & & & SS & $\mathrm{CC}$ & $\mathbf{C F}$ \\
\hline \multirow{10}{*}{5} & \multicolumn{2}{|c|}{ HBT [23] } & 48.5964 & 152.1588 & 13.0595 \\
\hline & \multicolumn{2}{|c|}{ Quasi-3D [24] } & 49.5906 & 160.2780 & 13.1224 \\
\hline & \multicolumn{2}{|c|}{ Quasi-3D [25] } & 49.5970 & 160.3064 & 13.1138 \\
\hline & \multirow{7}{*}{ Present } & 2 terms & 59.9462 & 169.2615 & 13.6065 \\
\hline & & 4 terms & 49.6171 & 160.5097 & 13.2304 \\
\hline & & 6 terms & 49.5906 & 160.3503 & 13.1653 \\
\hline & & 8 terms & 49.5906 & 160.3145 & 13.1289 \\
\hline & & 10 terms & 49.5906 & 160.2839 & 13.1178 \\
\hline & & 12 terms & 49.5906 & 160.2679 & 13.1140 \\
\hline & & 14 terms & 49.5906 & 160.2662 & 13.1115 \\
\hline \multirow{10}{*}{20} & \multicolumn{2}{|c|}{ HBT [23] } & 53.2364 & 208.9515 & 13.3730 \\
\hline & \multirow{2}{*}{\multicolumn{2}{|c|}{$\begin{array}{l}\text { Quasi-3D [24] } \\
\text { Ouasi-3D [25] }\end{array}$}} & 53.3145 & 210.7420 & 13.3981 \\
\hline & & Quasi-3D [25] & 53.3175 & 210.7774 & 13.3993 \\
\hline & \multirow{7}{*}{ Present } & 2 terms & 65.7932 & 239.9515 & 13.8748 \\
\hline & & 4 terms & 53.3455 & 212.3740 & 13.4792 \\
\hline & & 6 terms & 53.3145 & 211.4672 & 13.4313 \\
\hline & & 8 terms & 53.3145 & 211.0324 & 13.4126 \\
\hline & & 10 terms & 53.3145 & 210.8367 & 13.4040 \\
\hline & & 12 terms & 53.3145 & 210.7416 & 13.3996 \\
\hline & & 14 terms & 53.3145 & 210.6946 & 13.3971 \\
\hline
\end{tabular}


Regarding to the numerical results for the dimensionless critical buckling loads given in Table 4, it is clear that for SS beams, the computed first critical buckling loads show excellent agreement when the number of terms in the displacement functions is set to 6 . Agreed results are obtained as the number of terms in the displacement functions is set to 10 for $\mathrm{CC}$ and $\mathrm{CF}$ beams. The computed results based on the present Quasi - 3D theory is higher than the ones obtained by the HBT theory. The extensive studies based on the buckling behavior of two directional FGBs are performed by employing 12 terms in the displacement functions. In Tables 5-8, the first three dimensionless frequencies of the 2D-FGBs with SS, $\mathrm{CS}, \mathrm{CC}$ and CF boundary conditions are presented for two different aspect ratios (L/h=5 and 20) and various gradient indexes in both directions $\left(\mathrm{p}_{z}\right.$ and $\left.\mathrm{p}_{\mathrm{x}}\right)$. It is observed that that the first three dimensionless frequencies decrease for all type of end conditions except CF beams while the gradient indexes increase. For CF beams with $p_{x} \geq 2$, the dimensionless fundamental frequencies increase as the gradient index in the $\mathrm{z}$ direction increases for the studied aspect ratios. Moreover, the second dimensionless frequencies of CF beams with $p_{x}=10$ increase as the gradient index in the $\mathrm{z}$ direction increases. And finally, the third dimensionless frequencies of CF beams with $p_{x} \geq 5$ increase as the gradient index in the $\mathrm{z}$ direction increases only for the aspect ratio 5. It is expected that the frequencies have to decrease since the Young's modulus, ultimately the rigidity of the beam decreases with the increase of the gradient indexes. However, the mass is not constant and decreased by the material gradient indexes. It is very well known in vibration theory and should be noted that the frequency is inversely proportional with the mass of the beam. It is clear that the effect of the mass on the first three dimensionless frequencies of the SS, CS and CC beams is a bit more dominant than the effect of the Young's modulus.

Table 5. The first three dimensionless frequencies of SS two directional FGBs with respect to gradient index and aspect ratio change.

\begin{tabular}{|c|c|c|c|c|c|c|c|c|c|c|c|c|c|}
\hline \multirow{3}{*}{$\lambda$} & \multicolumn{13}{|c|}{$\mathbf{p}_{\mathbf{z}}$} \\
\hline & \multirow[t]{2}{*}{$\mathbf{p}_{\mathrm{x}}$} & $L / h=5$ & \multicolumn{11}{|c|}{$\mathrm{L} / \mathrm{h}=\mathbf{2 0}$} \\
\hline & & $\mathbf{0}$ & 0.5 & 1 & 2 & 5 & 10 & $\begin{array}{l} \\
\end{array}$ & 0.5 & 1 & 2 & 5 & 10 \\
\hline \multirow{6}{*}{$\lambda_{1}$} & $\mathbf{0}$ & 5.1616 & 4.4236 & .0073 & 3.6434 & 3.4126 & 3.2898 & 5.4610 & 4.6658 & 4.2345 & 3.8763 & 3.6822 & 3.5589 \\
\hline & 0.5 & 4.6312 & & 7065 & & 2724 & 3.1586 & 4.9210 & 4.2586 & 3.9284 & 3.6711 & 3.5172 & 3.3958 \\
\hline & 1 & 4.1791 & 3.7055 & 3.4744 & 3.2888 & 3.1504 & 3.0499 & 4.4310 & 3.9173 & 3.6762 & 3.4936 & 3.3703 & 3.2634 \\
\hline & 2 & 3.5772 & 3.3007 & 3.1727 & 3.0685 & 2.9758 & 2.9045 & 3.7660 & 3.4718 & 3.3414 & 3.2435 & 3.1642 & 3.0912 \\
\hline & 5 & 2.9643 & 2.8841 & 8468 & & 2.7758 & 2.7488 & 3.1030 & 3.0222 & 2.9 & 620 & 2.9360 & \\
\hline & 10 & 2.7726 & 2.7493 & 373 & 2.7 & 2.7092 & 2.6997 & 2.9071 & 2.8860 & 2.8773 & 705 & 2.8630 & 2.8564 \\
\hline \multirow{6}{*}{$\lambda_{2}$} & $\mathbf{0}$ & 15.8455 & 9581 & 700 & 32 & & 9.2152 & 21.5835 & & 16.7400 & 000 & 14.4865 & 13.9937 \\
\hline & 0.5 & 12.0062 & 11.1381 & 0.5612 & 9.9133 & .1984 & 8.8160 & 19.2395 & 16.6946 & & 158 & .7879 & 3.3164 \\
\hline & 1 & 10.0770 & 9.7108 & 9.4647 & 9.1 & 8.7745 & 8.5557 & 17.3484 & 15.3895 & 14.4511 & 186 & 13.2 & 12.8205 \\
\hline & 2 & 8.6965 & 8.6391 & 8.5833 & 8.5011 & 8.3895 & 8.3277 & 15.1628 & 13.9183 & 13.3337 & 787 & 12.54 & 2.268 \\
\hline & 5 & 8.0148 & 8.0946 & 8.1297 & 8.1630 & 8.1983 & 8.2155 & 12.9496 & 12.4183 & 12.1807 & 9976 & 11.8380 & 1.694 \\
\hline & 10 & 7.9888 & 8.0690 & 8.1092 & 8.1497 & 8.1913 & 8.2105 & 11.8844 & 11.6838 & 11.5980 & 304 & 11.4606 & 11.398 \\
\hline \multirow{6}{*}{$\lambda_{3}$} & $\mathbf{0}$ & 17.9716 & \begin{tabular}{|l|}
15.7982 \\
\end{tabular} & \begin{tabular}{|l|}
14.6193 \\
\end{tabular} & 13.3673 & \begin{tabular}{|l|}
12.0190 \\
\end{tabular} & 11.2896 & 47.6417 & 40.7450 & 36.9057 & 081 & 31.6248 & 30.548 \\
\hline & 0.5 & 15.8647 & 13.9906 & 12.9844 & 12.04121 & 11.1769 & 10.7077 & 42.2638 & 36.7311 & 33.9375 & & 30.2317 & 29.200 \\
\hline & 1 & 14.3020 & \begin{tabular}{|l|}
12.8353 \\
\end{tabular} & 12.0631 & \begin{tabular}{ll|l}
1.3601 & 1 \\
\end{tabular} & \begin{tabular}{|l|}
10.7352 \\
\end{tabular} & 10.3812 & 38.0997 & 33.8924 & 31.8456 & 30.2096 & 29.0457 & 28.1740 \\
\hline & 2 & 12.5555 & \begin{tabular}{|l|}
11.6170 \\
\end{tabular} & \begin{tabular}{|l|}
11.1376 \\
\end{tabular} & 10.7059 & \begin{tabular}{|l|}
10.2974 \\
\end{tabular} & 10.0454 & 33.4581 & 30.7594 & 29.4675 & & 27.6526 & 27.040 \\
\hline & 5 & 10.7851 & 10.3884 & 10.1936 & 10.0111 & \begin{tabular}{|l|}
9.8061 \\
\end{tabular} & 9.6698 & 28.8297 & 27.5972 & 27.0195 & 26.5604 & 26.1796 & 25.861 \\
\hline & 10 & 9.9806 & \begin{tabular}{|l|}
9.8194 \\
\end{tabular} & \begin{tabular}{|l|}
9.7366 \\
\end{tabular} & 9.6493 & 9.5379 & 9.4692 & 26.6522 & 26.0903 & 25.8388 & 25.6381 & 25.4434 & 25.2749 \\
\hline
\end{tabular}


Karamanlı / Anadolu Univ. J. of Sci. and Technology A-Appl. Sci. and Eng. 19 (2) - 2018

Table 6. The first three dimensionless frequencies of CS two directional FGBs with respect to gradient index and aspect ratio change.

\begin{tabular}{|c|c|c|c|c|c|c|c|c|c|c|c|c|c|}
\hline \multirow{3}{*}{$\lambda$} & \multicolumn{13}{|c|}{$\mathbf{p}_{\mathbf{z}}$} \\
\hline & \multirow[t]{2}{*}{$\mathbf{p}_{\mathrm{x}}$} & $\mathrm{L} / \mathrm{h}=5$ & \multicolumn{11}{|c|}{$\mathrm{L} / \mathrm{h}=\mathbf{2 0}$} \\
\hline & & 0 & 0.5 & 1 & 2 & 5 & 10 & $\mathbf{0}$ & 0.5 & 1 & 2 & 5 & 10 \\
\hline \multirow{6}{*}{$\lambda_{1}$} & 0 & 7.6552 & 6.6074 & 6.0067 & 5.4570 & 5.0342 & 4.8103 & 8.5094 & 7.2741 & 6.6023 & 6.0420 & 5.7312 & 5.5356 \\
\hline & 0.5 & 6.3567 & 5.6592 & 5.2849 & 4.9519 & 4.6758 & 4.5131 & 6.9971 & 6.1958 & 5.7964 & 5.4853 & 5.2971 & 5.1431 \\
\hline & 1 & 5.7603 & 5.2358 & 4.9598 & 4.7156 & 4.5065 & 4.3792 & 6.3149 & 5.7242 & 5.4385 & 5.2207 & 5.0816 & 4.9588 \\
\hline & 2 & 5.1928 & 4.8393 & 4.6597 & 4.4986 & 4.3452 & 4.2475 & 5.6590 & 5.2746 & 5.0979 & 4.9655 & 4.8672 & 4.7747 \\
\hline & 5 & 4.5065 & 4.3661 & 4.2938 & 4.2207 & 4.1348 & 4.0829 & 4.8831 & 4.7442 & 4.6844 & 4.6385 & 4.5939 & 4.5523 \\
\hline & 10 & 4.1951 & 4.1439 & 4.1134 & 4.0798 & 4.0351 & 4.0112 & 4.5636 & 4.5215 & 4.5037 & 4.4893 & 4.4735 & 4.4597 \\
\hline \multirow{6}{*}{$\lambda_{2}$} & $\mathbf{0}$ & 15.8455 & 14.2559 & 13.2040 & 11.9300 & 10.3600 & 9.4973 & 27.1362 & 23.2313 & 21.0898 & 19.2763 & 18.2034 & 17.5525 \\
\hline & 0.5 & 12.0062 & 11.1856 & 10.6542 & \begin{tabular}{|l|}
10.0210 \\
\end{tabular} & 9.2537 & 8.8375 & 23.2137 & 20.3810 & 18.9464 & 17.7948 & 17.057 & 16.5150 \\
\hline & 1 & 10.0770 & 9.7128 & 9.4677 & \begin{tabular}{|l|l|}
9.1637 \\
\end{tabular} & 8.7748 & 8.5559 & 21.1411 & 18.9382 & 17.8570 & 17.0011 & 16.4223 & 15.9724 \\
\hline & 2 & 8.6965 & 8.6420 & 8.5906 & 8.5134 & 8.4010 & 8.3348 & 18.9078 & 17.4079 & 16.6928 & 16.1306 & 15.7215 & 15.3883 \\
\hline & 5 & 8.0148 & 8.0962 & 8.1333 & 8.1683 & 8.2026 & 8.2180 & 16.3260 & 15.6444 & 15.3353 & 15.0967 & 14.8958 & 14.7165 \\
\hline & 10 & 7.9888 & 8.0691 & 8.1095 & 8.1501 & 8.1916 & 8.2107 & 15.0092 & 14.7358 & 14.6186 & 14.5273 & 14.4362 & 14.3532 \\
\hline \multirow{6}{*}{$\lambda_{3}$} & 0 & 21.0092 & 18.3303 & 16.6967 & 15.0492 & 13.4913 & 12.7572 & 55.3449 & 47.4742 & 43.1077 & 39.3361 & 36.9305 & 35.5329 \\
\hline & 0.5 & 17.9388 & 15.9748 & 14.8466 & 13.7410 & 12.7143 & 12.2179 & 47.9082 & 41.9833 & 38.9482 & 36.4552 & 34.7599 & 33.6082 \\
\hline & 1 & 16.2359 & 14.7230 & 13.8783 & 13.0664 & 12.3229 & 11.9458 & 40.3079 & 38.7665 & 36.6664 & 34.8267 & 33.5090 & 32.5477 \\
\hline & 2 & 14.4376 & 13.4283 & 12.8877 & 12.3816 & 11.9126 & 11.6505 & 34.7862 & 34.5556 & 34.1544 & 32.9763 & 32.0645 & 31.3617 \\
\hline & 5 & 12.4407 & 12.0153 & 11.8041 & 11.6113 & 11.4112 & 11.2778 & 32.0591 & 32.0686 & 31.4021 & 30.8587 & 30.4045 & 30.0354 \\
\hline & 10 & 11.5509 & 11.3841 & 11.3031 & $\mid 11.2247$ & 11.1294 & 11.0649 & 31.0525 & 30.3768 & 30.0691 & 29.8196 & 29.5774 & 29.3748 \\
\hline
\end{tabular}

On the other hand, depending on the gradient index in the $\mathrm{x}$ direction, mode numbers and aspect ratios, the vibration behavior of the 2D- FGBs with CF boundary condition is significantly affected with the variation of the mass and Young's modulus. It is clear that the reduction in the dimensionless free vibration frequencies because of the gradient index variation in the $\mathrm{x}$ direction is more than the gradient index variation in the $\mathrm{z}$ direction for all type of end conditions. The highest free vibration frequencies for 2D-FGBs are obtained as the CC boundary condition is employed. As it is expected, the lowest frequencies are observed for CF beams followed by SS and CS beams.

Table 7. The first three dimensionless frequencies of CC two directional FGBs with respect to gradient index and aspect ratio change.

\begin{tabular}{|c|c|c|c|c|c|c|c|c|c|c|c|c|c|}
\hline \multirow{3}{*}{$\lambda$} & \multicolumn{13}{|c|}{$p_{z}$} \\
\hline & $\mathbf{p}_{\mathbf{x}}$ & \multicolumn{6}{|l|}{$\mathrm{L} / \mathrm{h}=5$} & \multicolumn{6}{|l|}{$\mathrm{L} / \mathrm{h}=\mathbf{2 0}$} \\
\hline & & $\begin{array}{l}\mathbf{0} \\
\end{array}$ & 0.5 & 1 & 2 & 5 & 10 & \begin{tabular}{|l|}
0 \\
\end{tabular} & 0.5 & 1 & 2 & 5 & 10 \\
\hline \multirow{6}{*}{$\lambda_{1}$} & $\mathbf{0}$ & 10.1759 & 8.8542 & 8.0672 & 7.2947 & 6.5887 & 6.2416 & 12.2721 & 10.4992 & 9.5300 & 8.7146 & 8.2446 & 7.9552 \\
\hline & 0.5 & 8.6837 & 7.7335 & 7.1984 & 6.6815 & 6.1950 & 5.9474 & 10.4425 & \begin{tabular}{|l|l|}
9.1841 \\
\end{tabular} & 8.5464 & 8.0341 & 7.7086 & 7.4680 \\
\hline & 1 & 8.0146 & 7.2454 & 6.8189 & 6.4068 & 6.0187 & 5.8206 & 9.6508 & 8.6350 & 8.1285 & 7.7202 & 7.4470 & 7.2446 \\
\hline & 2 & 7.4211 & 6.8138 & 6.4827 & 6.1621 & 5.8589 & 5.7035 & 8.9312 & 8.1392 & 7.7478 & 7.4274 & 7.1994 & 7.0345 \\
\hline & 5 & 6.7044 & 6.3084 & 6.0929 & 5.8831 & 5.6831 & 5.5777 & 8.1208 & 7.5925 & 7.3283 & 7.1056 & 6.9363 & 6.8177 \\
\hline & 10 & 6.2354 & 5.9793 & 5.8418 & 5.7098 & 5.5829 & 5.5105 & 7.6339 & 7.2699 & 7.0859 & 6.9279 & 6.8005 & 6.7087 \\
\hline \multirow{6}{*}{$\lambda_{2}$} & $\mathbf{0}$ & 24.3589 & 21.3564 & 19.4838 & 17.5186 & 15.5157 & 14.5968 & 33.2845 & 28.5171 & 25.8895 & 23.6467 & 22.2759 & 21.4594 \\
\hline & 0.5 & 21.1061 & 18.8226 & 17.4750 & 16.0908 & 14.6829 & 14.0309 & 28.7587 & 25.2140 & 23.4044 & 21.9294 & 20.9462 & 20.2556 \\
\hline & 1 & 19.2354 & 17.4322 & 16.3953 & 15.3416 & 14.2693 & 13.7605 & 26.3398 & 23.5295 & 22.1316 & 20.9986 & 20.2035 & 19.6256 \\
\hline & 2 & 17.2189 & 15.9694 & 15.2693 & 14.5617 & 13.8333 & 13.4745 & 23.7650 & 21.7720 & 20.7950 & 19.9962 & 19.4007 & 18.9640 \\
\hline & 5 & 15.1832 & 14.4989 & 14.1212 & 13.7415 & 13.3534 & 13.1571 & 21.0582 & 19.9316 & 19.3703 & 18.8965 & 18.5278 & 18.2667 \\
\hline & 10 & 14.3429 & 13.8876 & 13.6351 & 13.3837 & 13.1361 & 13.0123 & 19.8630 & 19.1102 & 18.7254 & 28.3937 & 18.1345 & 17.9567 \\
\hline \multirow{6}{*}{$\lambda_{3}$} & $\mathbf{0}$ & 31.6911 & 28.5167 & 26.4184 & 23.8732 & 20.7275 & 18.9992 & 63.3236 & 54.4023 & 49.4097 & 45.0337 & 42.0880 & 40.4225 \\
\hline & 0.5 & 26.9491 & 24.5911 & 23.0946 & 21.3277 & 19.2155 & 18.0898 & 55.0410 & 48.2705 & 44.7633 & 41.8264 & 39.7191 & 38.3415 \\
\hline & 1 & 24.8720 & 22.9287 & 21.7150 & 20.2962 & 18.6227 & 17.7392 & 50.1770 & 44.8691 & 42.2028 & 39.9891 & 38.3169 & 37.1679 \\
\hline & 2 & 23.2602 & 21.6318 & 20.6357 & 19.4897 & 18.1606 & 17.4672 & 44.8669 & 41.2414 & 39.4503 & 37.9492 & 36.7350 & 35.8824 \\
\hline & 5 & 20.8850 & 19.8707 & 19.2443 & 18.5099 & 17.6318 & 17.1623 & 39.4386 & 37.5307 & 36.5711 & 35.7345 & 35.0129 & 34.5259 \\
\hline & 10 & 19.0593 & 18.5083 & 18.1557 & 17.7273 & 17.1985 & 16.9091 & 37.1394 & 35.9281 & 35.2980 & 34.7303 & 34.2408 & 33.9319 \\
\hline
\end{tabular}


Karamanlı / Anadolu Univ. J. of Sci. and Technology A-Appl. Sci. and Eng. 19 (2) - 2018

Table 8. The first three dimensionless frequencies of CF two directional FGBs with respect to gradient index and aspect ratio change.

\begin{tabular}{|c|c|c|c|c|c|c|c|c|c|c|c|c|c|}
\hline \multirow{3}{*}{$\lambda$} & \multicolumn{13}{|c|}{$\mathbf{p}_{\mathbf{z}}$} \\
\hline & \multirow[t]{2}{*}{$\mathbf{p}_{\mathbf{x}}$} & $\mathrm{L} / \mathrm{h}=\mathbf{5}$ & & & & & & $L / h=20$ & & & & & \\
\hline & & 0 & 0.5 & 1 & 2 & 5 & 10 & 0 & 0.5 & 1 & 2 & 5 & 10 \\
\hline \multirow{6}{*}{$\lambda_{1}$} & $\mathbf{0}$ & 1.9053 & 1.6311 & 1.4803 & 1.3523 & 1.2762 & 1.2308 & 1.9531 & 1.6684 & 1.5141 & 1.3863 & 1.3176 & 1.2737 \\
\hline & 0.5 & 1.3346 & 1.2291 & 1.1802 & 1.1455 & 1.1225 & 1.0972 & 1.3585 & 1.2510 & 1.2030 & 1.1715 & 1.1542 & 1.1299 \\
\hline & 1 & 1.0953 & 1.0646 & 1.0534 & 1.0491 & 1.0474 & 1.0378 & 1.1137 & 1.0834 & 1.0736 & 1.0722 & 1.0746 & 1.0660 \\
\hline & 2 & 0.9526 & 0.9640 & 0.9724 & 0.9837 & 0.9956 & 0.9980 & 0.9703 & 0.9829 & 0.9927 & 1.0059 & 1.0203 & 1.0235 \\
\hline & 5 & 0.9134 & 0.9366 & 0.9493 & 0.9628 & 0.9769 & 0.9832 & 0.9333 & 0.9577 & 0.9713 & 0.9858 & 1.0010 & 1.0078 \\
\hline & 10 & 0.9322 & 0.9503 & 0.9598 & 0.9 & 0.9796 & & 0.9539 & \begin{tabular}{|l|}
0.9729 \\
\end{tabular} & 0.9 & 0.9 & 1.0040 & 089 \\
\hline \multirow{6}{*}{$\lambda_{2}$} & $\mathbf{0}$ & 10.3117 & 8.9194 & 8.1010 & 7.3287 & 6.7064 & 6.4024 & 12.1046 & 10.3504 & 9.3940 & 8.5933 & 8.1431 & 7.8632 \\
\hline & 0.5 & 8.3747 & 7.4849 & 6.9919 & 6.5473 & 6.2046 & 6.0242 & 9.9084 & 8.7781 & 8.2166 & 7.7819 & 7.5199 & 7.3028 \\
\hline & 1 & 7.3529 & 6.7574 & 6.4400 & 6.1684 & 5.9675 & 5.8429 & 8.8103 & 8.0170 & 7.6411 & 7.3623 & 7.1852 & 7.0173 \\
\hline & 2 & 6.3992 & 6.0889 & 5.9395 & 5.8215 & 5.7259 & 5.6464 & 7.6910 & 7.2467 & 7.0541 & 6.9209 & 6.8226 & 6.7129 \\
\hline & 5 & 5.5417 & 5.4874 & 5.4677 & 5.4556 & 5.4410 & 5.4222 & 6.5254 & 6.4440 & 6.4201 & 6.4131 & 6.4077 & 6.3852 \\
\hline & 10 & 5.2869 & 5.3090 & 5.3220 & 5.3362 & 5.3503 & 5.3555 & 6.1781 & 6.2076 & 6.2286 & 6.2541 & 6.2809 & 6.2897 \\
\hline \multirow{6}{*}{$\lambda_{3}$} & $\mathbf{0}$ & 15.8455 & 14.2627 & 13.2203 & 11.9578 & 10.3905 & 9.5189 & 33.3095 & 28.5237 & 25.8911 & 23.6527 & 22.3137 & 21.5126 \\
\hline & 0.5 & 12.0062 & 11.2003 & 10.6888 & 10.0767 & 9.3064 & 8.8689 & 28.4234 & 24.9643 & 23.2121 & 21.8068 & 20.9086 & 20.2493 \\
\hline & 1 & 10.0770 & 9.7236 & 9.4905 & 9.1969 & 8.8026 & 8.5709 & 25.7063 & 23.0718 & 21.7861 & 20.7774 & 20.0984 & \\
\hline & 2 & 8.6965 & 8.6428 & 8.5920 & & 8.4030 & & 22.7193 & 21.0179 & 20.2227 & 19.6138 & 19.1709 & 18.7867 \\
\hline & 5 & 8.0148 & 8.0960 & 8.1331 & 8.1681 & 8.2027 & 8.2181 & 19.2706 & 18.6485 & 18.3884 & 18.2051 & 18.0462 & 17.8799 \\
\hline & 10 & 7.9888 & 8.0693 & 8.1098 & 8.1505 & 8.1919 & 8.2108 & 17.6872 & 17.5547 & 17.5157 & 17.5014 & 17.4868 & 17.4500 \\
\hline
\end{tabular}

Table 9. The first three dimensionless critical buckling loads of SS two directional FGBs with respect to gradient index and aspect ratio change.

\begin{tabular}{|c|c|c|c|c|c|c|c|c|c|c|c|c|c|}
\hline \multirow{3}{*}{$\lambda$} & \multicolumn{13}{|c|}{$\mathbf{p}_{\mathbf{z}}$} \\
\hline & \multirow[t]{2}{*}{$\mathbf{p}_{\mathrm{x}}$} & $L / h=5$ & & & & & & $L / h=20$ & & & & & \\
\hline & & 0 & 0.5 & 1 & 2 & 5 & 10 & 0 & 0.5 & 1 & 2 & 5 & 10 \\
\hline \multirow{6}{*}{$\bar{N}_{c r 1}$} & 0 & 49.5906 & 32.6756 & 25.3504 & 19.7589 & 16.1607 & 14.4341 & \begin{tabular}{|l|}
53.3145 \\
\end{tabular} & 34.8027 & 26.9773 & 21.1935 & 17.8416 & 16.1152 \\
\hline & 0.5 & 35.3718 & 24.7602 & 20.2383 & \begin{tabular}{|l|}
16.7963 \\
\end{tabular} & 14.4031 & 13.0663 & 38.6353 & 26.6992 & 21.7735 & \begin{tabular}{|l|}
18.1772 \\
\end{tabular} & 15.8911 & 14.4704 \\
\hline & \begin{tabular}{|l|l}
1 \\
\end{tabular} & 26.1885 & 19.6987 & 16.9169 & 14.7498 & 13.0797 & 12.0455 & 28.6050 & 21.2395 & 18.2024 & 15.9510 & 14.3482 & 13.2370 \\
\hline & 2 & 17.4341 & 14.6332 & 13.3924 & 12.3669 & 11.4373 & 10.8086 & 18.7056 & 15.6087 & 14.2949 & \begin{tabular}{|l|}
13.2767 \\
\end{tabular} & 12.4178 & 11.7586 \\
\hline & 5 & 11.3382 & 10.7095 & 10.4114 & 10.1341 & 9.8266 & 9.6188 & 11.9565 & 11.3058 & 11.0224 & 10.7906 & 10.5563 & 10.3641 \\
\hline & 10 & 9.8204 & 9.6441 & 9.5527 & 9.4560 & 9.3367 & 9.2648 & 10.3666 & 10.2033 & 10.1327 & \begin{tabular}{|l|}
10.0737 \\
\end{tabular} & 10.0101 & 9.9585 \\
\hline \multirow{6}{*}{$\bar{N}_{c r 2}$} & \begin{tabular}{|l|l|} 
\\
\end{tabular} & 160.0767 & 107.9494 & \begin{tabular}{|l|}
84.0471 \\
\end{tabular} & 64.3616 & 49.2866 & 42.9415 & 210.1443 & 137.4481 & 106.5598 & \begin{tabular}{|l|}
83.5726 \\
\end{tabular} & 69.9215 & 63.0022 \\
\hline & 0.5 & 99.7755 & 76.0225 & 63.5501 & 52.6607 & 43.5556 & 39.236 & 146.3685 & 102.4113 & 84.0710 & 70.4563 & 61.5106 & 56.0840 \\
\hline & 1 & 67.8901 & 59.2406 & 52.3923 & 45.8828 & 39.9031 & 36.7749 & 108.2079 & 81.7264 & 70.4370 & 61.8009 & 55.5820 & 51.4940 \\
\hline & 2 & 53.3409 & 46.5659 & 42.9634 & 39.5345 & 36.1287 & 34.1773 & 76.0689 & 63.2377 & 57.4964 & 52.9287 & 49.3324 & 46.7737 \\
\hline & 5 & 38.8884 & 36.4863 & 35.2309 & 33.9732 & 32.5183 & 31.5949 & 52.4749 & 48.3128 & 46.4090 & 44.8394 & 43.3775 & 42.2166 \\
\hline & 10 & 33.5665 & 32.6266 & 32.1119 & 31.5397 & 30.7894 & 30.3305 & 43.7292 & 42.2854 & 41.6358 & 41.0852 & 40.5033 & 40.0313 \\
\hline \multirow{6}{*}{$\bar{N}_{c r 3}$} & 0 & 264.1664 & 182.3956 & 143.0163 & 108.0719 & 78.0393 & 666.494 & 461.4928 & 302.8028 & ( & 183.6713 & 152.1656 & 136.5831 \\
\hline & 0.5 & 111.4783 & 89.1194 & 81.4191 & 74.5207 & 66.9518 & 61.2813 & 316.6054 & 223.1402 & 183.6237 & 153.783 & 133.4832 & 121.6130 \\
\hline & 1 & 76.0445 & 65.1351 & 62.6508 & 60.6303 & 58.4825 & 57.2290 & 234.6189 & 178.4620 & 154.0632 & 135.0305 & 120.9720 & 112.0977 \\
\hline & 2 & 57.3314 & 56.4273 & 56.0330 & 55.6369 & 55.1667 & 54.7658 & 167.2355 & 139.3827 & 126.6949 & 116.3829 & 108.1004 & 102.4613 \\
\hline & 5 & 54.7570 & 54.6089 & 54.5360 & 54.4559 & 52.9070 & 51.5710 & 117.3598 & 107.6882 & 103.1064 & 99.2438 & 95.7556 & 93.1277 \\
\hline & 10 & 54.4277 & 53.4927 & 52.8044 & 51.9771 & 50.8003 & 50.0612 & 98.9708 & 95.0530 & 93.2189 & 91.6397 & 90.0193 & 88.7342 \\
\hline
\end{tabular}


Karamanl, / Anadolu Univ. J. of Sci. and Technology A-Appl. Sci. and Eng. 19 (2) - 2018

Table 10. The first three dimensionless critical buckling loads of CS two directional FGBs with respect to gradient index and aspect ratio change.

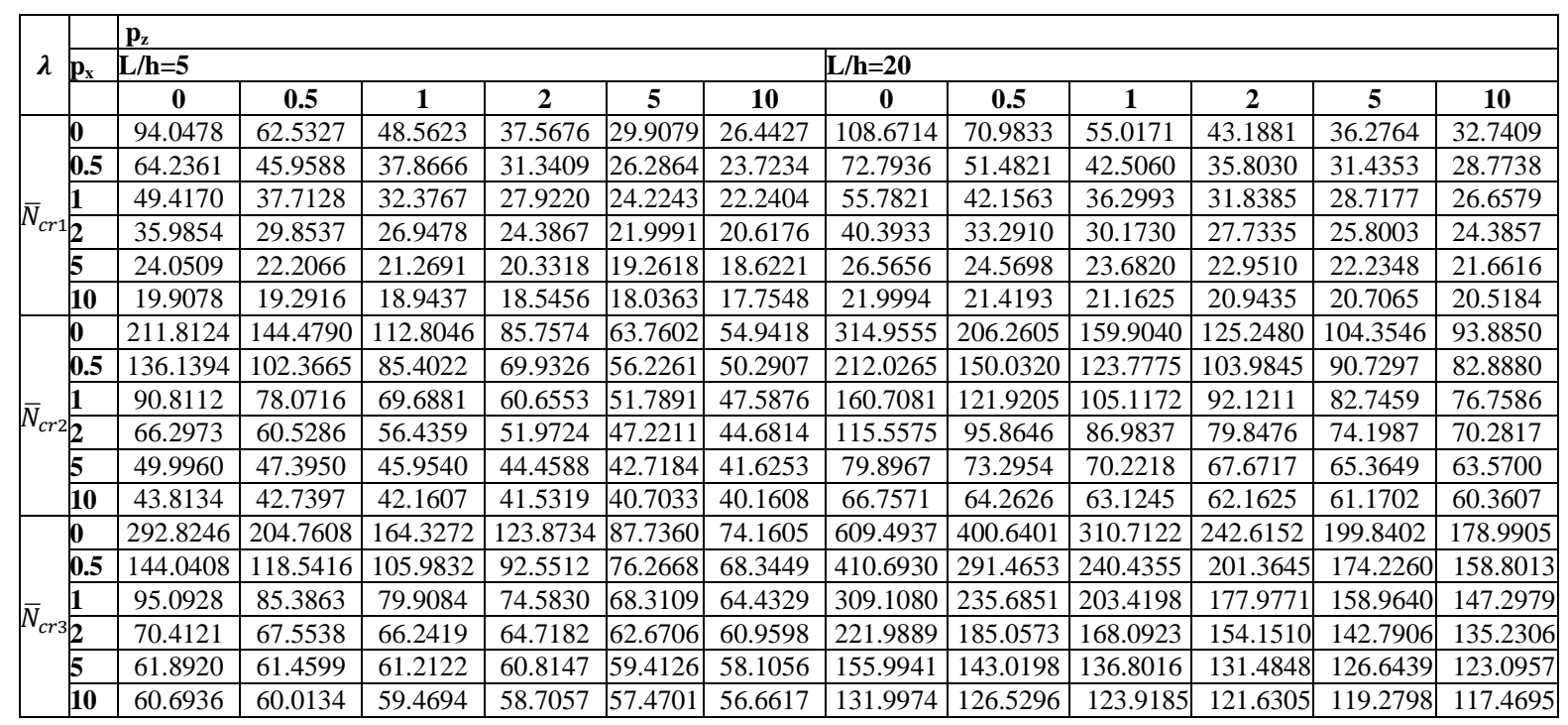

Table 11. The first three dimensionless critical buckling loads of CC two directional FGBs with respect to gradient index and aspect ratio change.

\begin{tabular}{|c|c|c|c|c|c|c|c|c|c|c|c|c|c|}
\hline \multirow{3}{*}{$\lambda$} & \multicolumn{13}{|c|}{$\mathbf{p}_{\mathrm{z}}$} \\
\hline & \multirow[t]{2}{*}{$\mathbf{p}_{\mathbf{x}}$} & $L / h=5$ & & & & & & $L / h=20$ & & & & & \\
\hline & & 0 & 0.5 & 1 & 2 & 5 & 10 & 0 & 0.5 & 1 & 2 & 5 & 10 \\
\hline \multirow{6}{*}{$N_{c r 1}$} & $\mathbf{0}$ & 160.2679 & 108.0746 & 84.1405 & 64.4273 & 49.3327 & 42.9835 & 210.7416 & 137.8225 & 106.8192 & 83.7477 & 70.0605 & 63.1383 \\
\hline & 0.5 & 105.7401 & \begin{tabular}{|l|}
77.2659 \\
\end{tabular} & 64.0343 & 52.6920 & 43.2038 & 38.8848 & 139.4402 & \begin{tabular}{|l|}
99.0554 \\
\end{tabular} & \begin{tabular}{|l|}
81.9713 \\
\end{tabular} & \begin{tabular}{|l|}
69.1074 \\
\end{tabular} & 60.5477 & 55.4082 \\
\hline & 1 & 78.0764 & 61.8422 & 53.6846 & 46.2912 & 39.7660 & 36.6520 & 106.2280 & 80.8979 & 69.8762 & \begin{tabular}{|l|}
61.3217 \\
\end{tabular} & 55.2183 & 51.3267 \\
\hline & 2 & 56.5523 & 48.5790 & 44.2899 & 40.1780 & 36.3473 & 34.3886 & 78.3073 & \begin{tabular}{|l|}
64.8021 \\
\end{tabular} & 58.6424 & \begin{tabular}{|l|}
53.6657 \\
\end{tabular} & 49.8535 & 47.2692 \\
\hline & 5 & \begin{tabular}{|l|}
41.1913 \\
\end{tabular} & 38.0888 & 36.3760 & 34.6960 & 33.0948 & 32.1795 & 57.1720 & 51.5890 & 48.8771 & 46.5946 & 44.7484 & 43.4120 \\
\hline & 10 & 35.8429 & 34.2305 & 33.3642 & 32.5459 & 31.7765 & 31.2651 & 49.7673 & 46.6931 & 45.1599 & \begin{tabular}{|l|}
43.8403 \\
\end{tabular} & 42.7116 & 41.8475 \\
\hline \multirow{6}{*}{$N_{c r 2}$} & $\mathbf{0}$ & 251.8003 & 173.3470 & 135.7595 & 102.7153 & 74.6796 & 63.8030 & 422.1958 & 276.9177 & 214.6817 & 167.9352 & 139.3281 & 125.1559 \\
\hline & 0.5 & 140.6232 & 113.5445 & 99.1277 & 82.3642 & 65.7591 & 58.7161 & 285.3990 & 201.9474 & 166.4983 & 139.6432 & 121.4228 & 110.8093 \\
\hline & $\mathbf{1}$ & 92.6954 & 81.5196 & 76.1113 & 69.4834 & 60.3112 & 55.6219 & 214.9611 & 163.3481 & 140.8976 & 123.4100 & 110.6102 & 102.5673 \\
\hline & 2 & \begin{tabular}{|l|}
67.2009 \\
\end{tabular} & 64.4927 & \begin{tabular}{|l|}
62.7682 \\
\end{tabular} & 59.6803 & 54.9978 & 52.3587 & 153.5458 & 127.8516 & 116.1476 & 106.6198 & 99.0132 & 93.8715 \\
\hline & 5 & \begin{tabular}{|l|}
57.4832 \\
\end{tabular} & 55.0799 & 53.6152 & 52.0247 & 50.2484 & 49.210 & 108.5457 & 99.3005 & 94.8022 & 90.9626 & 87.7387 & 85.4468 \\
\hline & 10 & 52.4406 & 51.0256 & 50.2111 & 49.3769 & 48.5227 & 48.0110 & 94.6575 & 89.8152 & \begin{tabular}{|l|}
87.3699 \\
\end{tabular} & \begin{tabular}{|l|}
85.2529 \\
\end{tabular} & 83.5097 & 82.2518 \\
\hline \multirow{6}{*}{$\bar{N}_{c r 3}$} & $\mathbf{0}$ & 311.1587 & 219.3574 & 181.7947 & 137.2511 & 95.7992 & 80.3945 & 795.1563 & 523.8922 & 406.3604 & 316.6468 & 258.9558 & 231.3145 \\
\hline & 0.5 & 146.7609 & 118.1641 & 105.9149 & 93.1985 & 78.5036 & 71.89405 & 532.5170 & 379.3240 & 313.200 & 262.004 & 225.670 & 205.5308 \\
\hline & 1 & 94.0713 & 84.9945 & 80.7869 & 75.1537 & 68.1386 & 65.28103 & 399.6407 & 306.1667 & 264.5835 & 231.3315 & 200.0308 & 190.9367 \\
\hline & 2 & 71.8621 & 68.1747 & 65.8363 & 63.6533 & 61.9527 & 61.13162 & 288.5471 & 241.2640 & 219.1959 & 200.7525 & 185.579 & 175.8422 \\
\hline & 5 & 60.5675 & 60.1987 & 59.9896 & 59.7456 & 59.4106 & 59.1633 & 207.0082 & 189.1032 & 180.2318 & 172.4511 & 165.6786 & 161.0968 \\
\hline & 10 & 59.3557 & 59.1538 & 59.0433 & 58.9077 & 58.6958 & 58.52021 & 179.3977 & 170.1427 & 165.3928 & 161.1602 & 157.5113 & 154.9999 \\
\hline
\end{tabular}


Karamanlı / Anadolu Univ. J. of Sci. and Technology A-Appl. Sci. and Eng. 19 (2) - 2018

Table 12. The first three dimensionless critical buckling loads of CF two directional FGBs with respect to gradient index and aspect ratio change.

\begin{tabular}{|c|c|c|c|c|c|c|c|c|c|c|c|c|c|}
\hline \multirow{3}{*}{$\lambda$} & \multicolumn{13}{|c|}{$\mathbf{p}_{\mathbf{z}}$} \\
\hline & \multicolumn{7}{|c|}{$p_{x} L / h=5$} & \multicolumn{6}{|l|}{$L / h=20$} \\
\hline & & 0 & 0.5 & 1 & 2 & 5 & 10 & 0 & 0.5 & 1 & 2 & 5 & 10 \\
\hline \multirow{6}{*}{$N_{c r 1}$} & $\mathbf{0}$ & 13.1140 & 8.5785 & 6.6516 & 5.2168 & 4.3630 & 3.9305 & 13.3996 & 8.7421 & 6.7750 & 5.3238 & 4.4887 & 4.0573 \\
\hline & 0.5 & 7.1664 & 5.3152 & 4.5423 & 3.9601 & 3.5352 & 3.2533 & 7.2264 & 5.3622 & 4.5899 & 4.0166 & 3.6135 & 3.3355 \\
\hline & \begin{tabular}{|l|}
1 \\
\end{tabular} & 4.8125 & 3.9772 & 3.6173 & 3.3332 & 3.0909 & 2.9153 & 4.8322 & 4.0009 & 3.6464 & 3.3726 & 3.1490 & 2.9789 \\
\hline & 2 & 3.3638 & 3.0718 & 2.9415 & 2.8324 & 2.7239 & 2.6415 & 3.3781 & 3.0908 & 2.9653 & 2.8646 & 2.7701 & 2.6933 \\
\hline & 5 & 2.6302 & 2.5715 & 2.5443 & 2.5192 & 2.4901 & 2.4689 & 2.6503 & 2.5955 & 2.5718 & 2.5524 & 2.5321 & 2.5152 \\
\hline & 10 & 2.4820 & 2.4663 & 2.4584 & 2.4502 & 2.4396 & 2.4325 & 2.5091 & 2.4967 & 2.4914 & 2.4871 & 2.4823 & 2.4785 \\
\hline \multirow{6}{*}{$N_{c r 2}$} & $\mathbf{0}$ & 94.0730 & 63.0249 & 49.5540 & 38.6896 & 30.6572 & 26.8840 & 119.3550 & 77.9738 & 60.4381 & 47.4398 & 39.8306 & 35.9419 \\
\hline & 0.5 & 64.3724 & 46.4348 & 38.5353 & 32.1033 & 26.9503 & 24.2522 & 77.6280 & 55.2534 & 45.8272 & 38.7754 & 34.1390 & 31.2951 \\
\hline & \begin{tabular}{|l|}
1 \\
\end{tabular} & 48.3869 & \begin{tabular}{|l|}
37.6100 \\
\end{tabular} & 32.6207 & 28.4151 & 24.8474 & 22.8254 & \begin{tabular}{|l|}
58.9276 \\
\end{tabular} & \begin{tabular}{|l|l|}
44.9463 \\
\end{tabular} & \begin{tabular}{|l|l|}
38.9154 \\
\end{tabular} & \begin{tabular}{|l|}
34.3060 \\
\end{tabular} & \begin{tabular}{|l|}
31.0667 \\
\end{tabular} & 28.9234 \\
\hline & 2 & 34.8564 & 29.5962 & 27.0581 & 24.8284 & 22.7131 & 21.3374 & 42.9238 & 35.6744 & 32.4723 & 29.9630 & 27.9889 & 26.5381 \\
\hline & 5 & 24.2830 & 22.6688 & 21.8744 & 21.1147 & 20.1978 & 19.5124 & 28.8986 & 26.8015 & 25.8675 & 25.1035 & 24.3623 & 23.7582 \\
\hline & 10 & 20.7495 & 20.1574 & 19.8418 & 19.4974 & 19.0084 & 18.6401 & 24.1295 & 23.5028 & 23.2275 & 22.9963 & 22.7482 & 22.5449 \\
\hline \multirow{6}{*}{$\bar{N}_{c r 3}$} & \begin{tabular}{|l|l|}
$\mathbf{0}$ \\
\end{tabular} & 150.0995 & 103.2808 & 84.9106 & 68.5902 & 52.1077 & 43.9219 & 324.8583 & 212.7835 & 164.9817 & 129.2274 & 107.6292 & 96.8097 \\
\hline & 0.5 & 122.3114 & \begin{tabular}{|l|l|}
88.5317 \\
\end{tabular} & 74.3293 & 61.6366 & 48.752 & 41.956 & 216.1440 & 153.360 & 126.756 & \begin{tabular}{|l|}
106.6771 \\
\end{tabular} & 93.1813 & 85.1794 \\
\hline & \begin{tabular}{|l|}
1 \\
\end{tabular} & 88.9437 & 73.6067 & 64.8398 & 56.1002 & 46.4543 & 40.7481 & 163.3633 & 124.4023 & 107.4885 & 94.3903 & 84.9201 & 78.8548 \\
\hline & 2 & 65.5538 & \begin{tabular}{|l|}
59.1107 \\
\end{tabular} & 54.7532 & 49.9332 & 43.7311 & 39.3138 & 117.9672 & 98.1425 & 89.1910 & 81.9929 & 76.2784 & 72.3031 \\
\hline & 5 & 50.7442 & 47.7075 & 45.8941 & 43.8063 & 40.4773 & 37.4451 & 82.2164 & 75.4954 & 72.3590 & 69.7490 & 67.3747 & 65.5315 \\
\hline & \begin{tabular}{|l|}
10 \\
\end{tabular} & 44.6512 & 43.1330 & 42.1785 & 40.9497 & 38.5491 & 36.1142 & 68.9235 & 66.3589 & 65.1825 & 64.1807 & 63.1358 & 62.2878 \\
\hline
\end{tabular}

The first three dimensionless critical buckling loads of the 2D-FGBs are revealed in Tables 9-12. It is clear that the first three critical buckling loads decrease for all type of end conditions as the gradient indexes increase. It is interesting that the shear deformation effect becomes significantly important as the buckling mode number increases. For all types of BCs, the relative difference between critical buckling loads with respect to variation of the aspect ratio increases as the buckling mode increases. The first dimensionless critical buckling loads of the 2D-FG CC beam with $\mathrm{p}_{z}=1$ and $\mathrm{p}_{\mathrm{x}}=1$ are $\bar{N}_{c r 1}=$ 53.6846 and $\bar{N}_{c r 1}=69.8762$ for $\mathrm{L} / \mathrm{h}=5$ and $\mathrm{L} / \mathrm{h}=20$, respectively. On the other hand, the third dimensionless critical buckling loads are $\bar{N}_{c r 3}=80.7869$ and $\bar{N}_{c r 1}=264.5835$ for $\mathrm{L} / \mathrm{h}=5$ and $\mathrm{L} / \mathrm{h}=20$, respectively. Using the value of the aspect ratio $\mathrm{L} / \mathrm{h}=5$ as a reference, the relative differences are $\% 30$ and $\% 228$ for $\mathrm{CC}$ beams with $\mathrm{L} / \mathrm{h}=5$ and $\mathrm{L} / \mathrm{h}=20$, respectively. For SS beams, the values are $\% 8$ and $\% 153$ for $\mathrm{L} / \mathrm{h}=5$ and $\mathrm{L} / \mathrm{h}=20$, respectively. The relative differences are $\% 35$ and $\% 202$ for CS beams with $\mathrm{L} / \mathrm{h}=5$ and $\mathrm{L} / \mathrm{h}=20$, respectively. And finally, for $\mathrm{CF}$ beams, they are $\% 3$ and $\% 107$ for $\mathrm{L} / \mathrm{h}=5$ and $\mathrm{L} / \mathrm{h}=20$, respectively. These results can be compared with ones given in [35]. It is clear that the relative difference is the least for CF beam while it is the most for CC beam. 


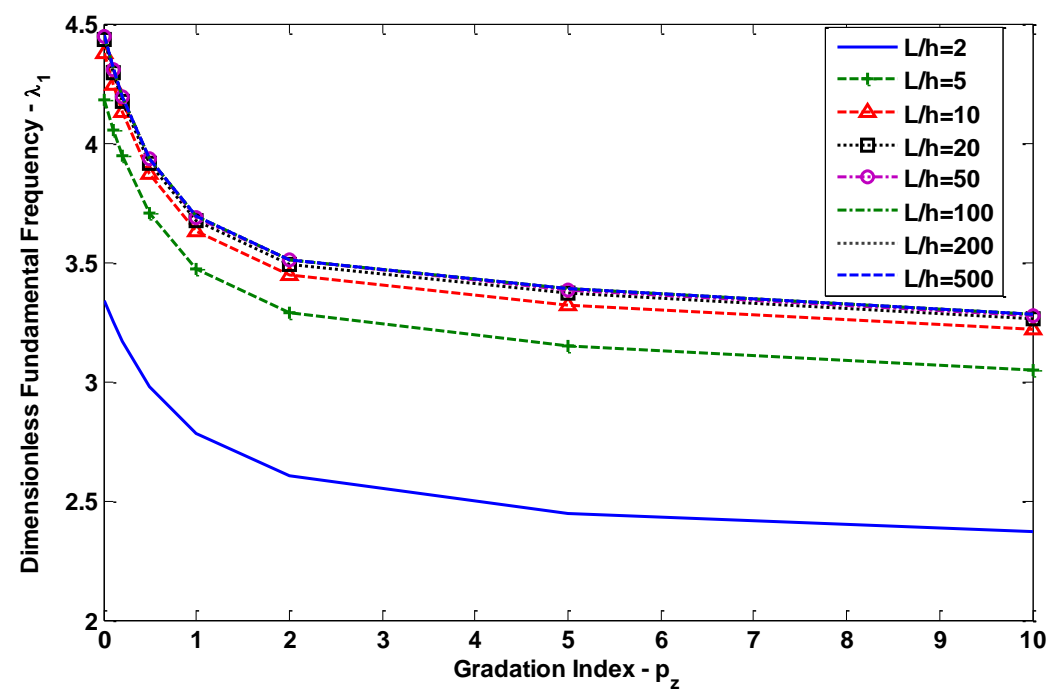

a) $\mathrm{p}_{\mathrm{x}}=1$

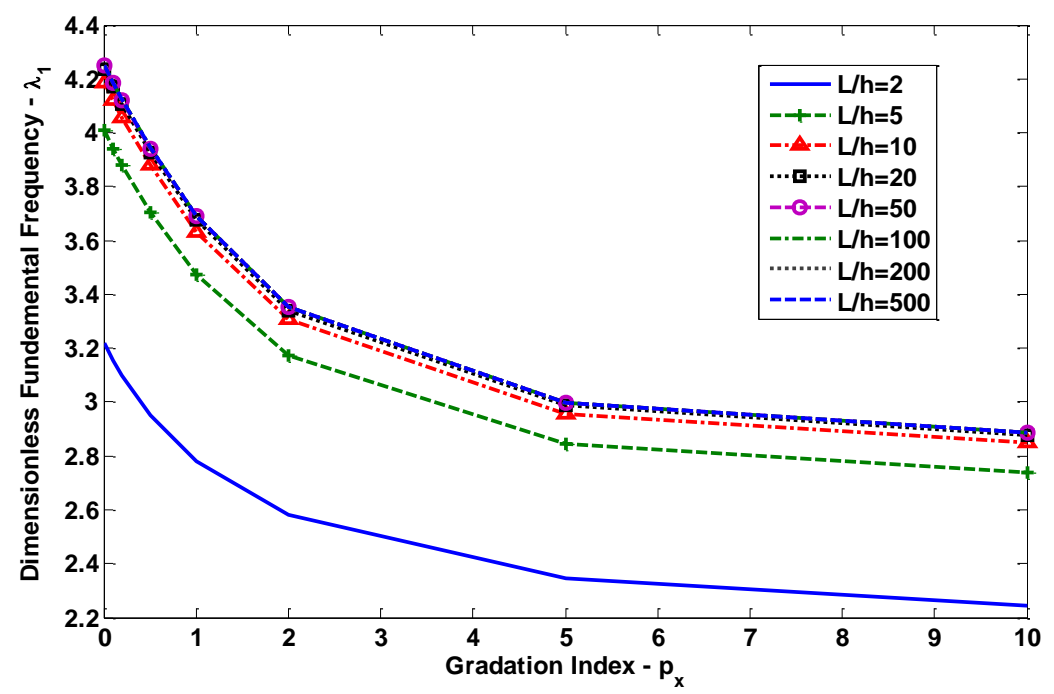

b) $\mathrm{p}_{\mathrm{z}}=1$

Figure 2. Variation of the dimensionless fundamental frequencies of SS two directional FGBs with respect to variation of gradient indexes and aspect ratios a) $p_{x}=1$ and b) $p_{z}=1$

Figures 2 to 5 are plotted to illustrate the effect of gradient indexes, px and pz, and aspect ratios on the dimensionless fundamental frequencies of the 2D-FGBs for all type of boundary conditions. It is observed that with the increase of the gradient indexes the dimensionless fundamental frequencies decrease because of decreasing the rigidity of the beam for SS, CS and CC beams. When the gradient index in the $\mathrm{z}$ direction is set to 1 , the dimensionless fundamental frequencies decrease with respect to variation of the gradient index in the $\mathrm{x}$ direction for all aspect ratios. Moreover, as the gradient index in the $\mathrm{x}$ direction is set to 1 , the dimensionless fundamental frequencies of CF 2D-FGBs decrease for the aspect ratio $L / h \leq 5$. For higher values of aspect ratio of CF 2D-FGBs with $p_{x}=1$ and $1 \leq p_{z} \leq$ 5 , the dimensionless fundamental frequencies increase. On the other hand, for CF 2D-FGBs with $L / h \geq 10, p_{x}=1$ and $5<p_{z} \leq 10$, the dimensionless fundamental frequencies decrease. As it is explained before, the vibration behavior of the 2D- FGBs with CF boundary condition is significantly 
affected with the variation of the mass and Young's modulus which depend on the gradient index in the $\mathrm{x}$ direction, mode numbers and aspect ratios.

It is found that the reduction in the dimensionless fundamental frequencies because of the gradient index variation in the $\mathrm{x}$ direction is more than the gradient index variation in the $\mathrm{z}$ direction for all boundary conditions and aspect ratios. According to the presented 2D- FGBs in Figures 2 to 5, the numerical results show that a thick $2 \mathrm{D}$ - FG beam can be defined with the aspect ratio $L / h \leq 10$ for the free vibration analysis except the CF beam with $p_{z}=1$ and $0<p_{x} \leq 10$.

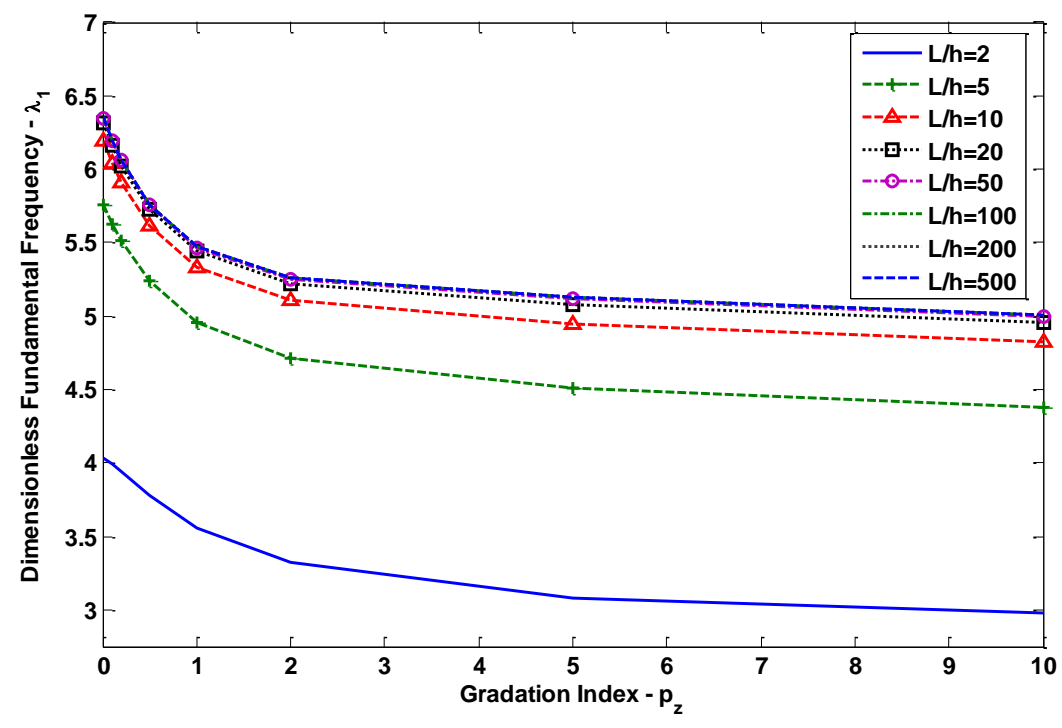

a) $\mathrm{p}_{\mathrm{x}}=1$

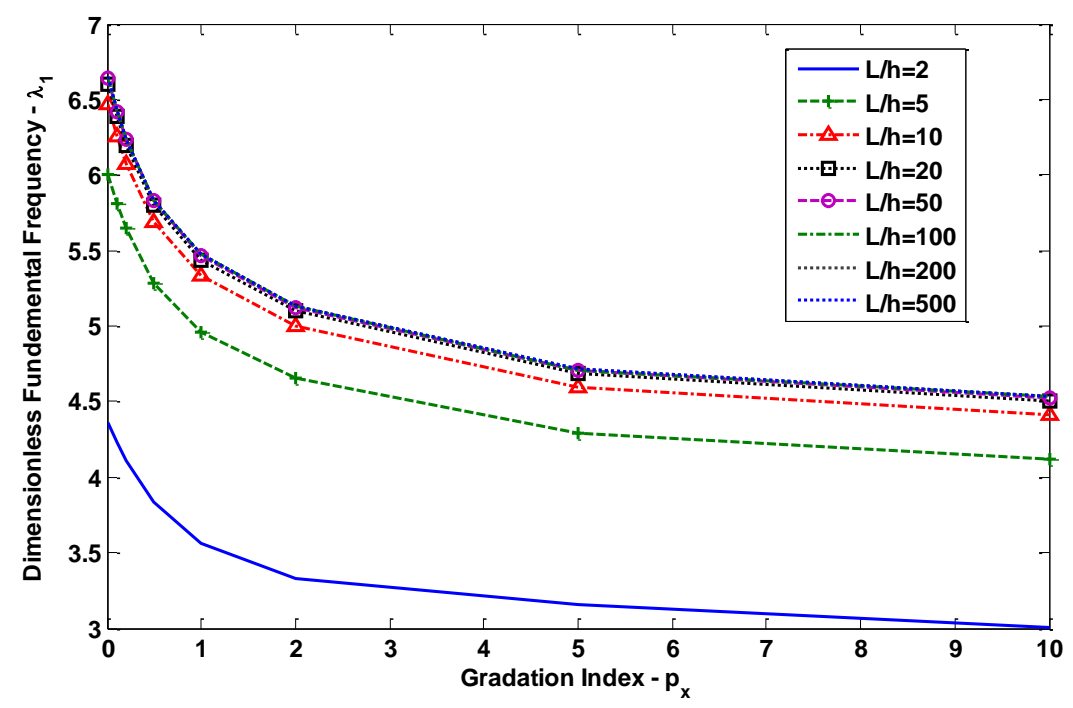

b) $\mathrm{p}_{z}=1$

Figure 3. Variation of the dimensionless fundamental frequencies of CS two directional FGBs with respect to variation of gradient indexes and aspect ratios a) $\mathrm{p}_{\mathrm{x}}=1$ and $\mathrm{b}$ ) $\mathrm{p}_{\mathrm{z}}=1$ 


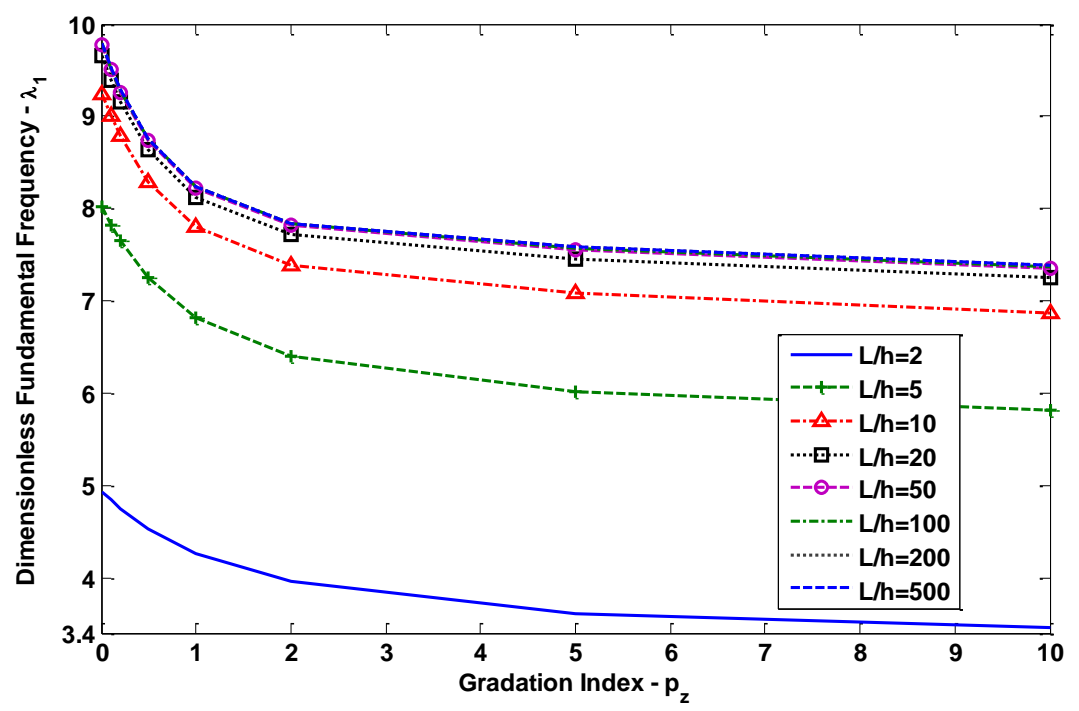

a) $\mathrm{p}_{\mathrm{x}}=1$

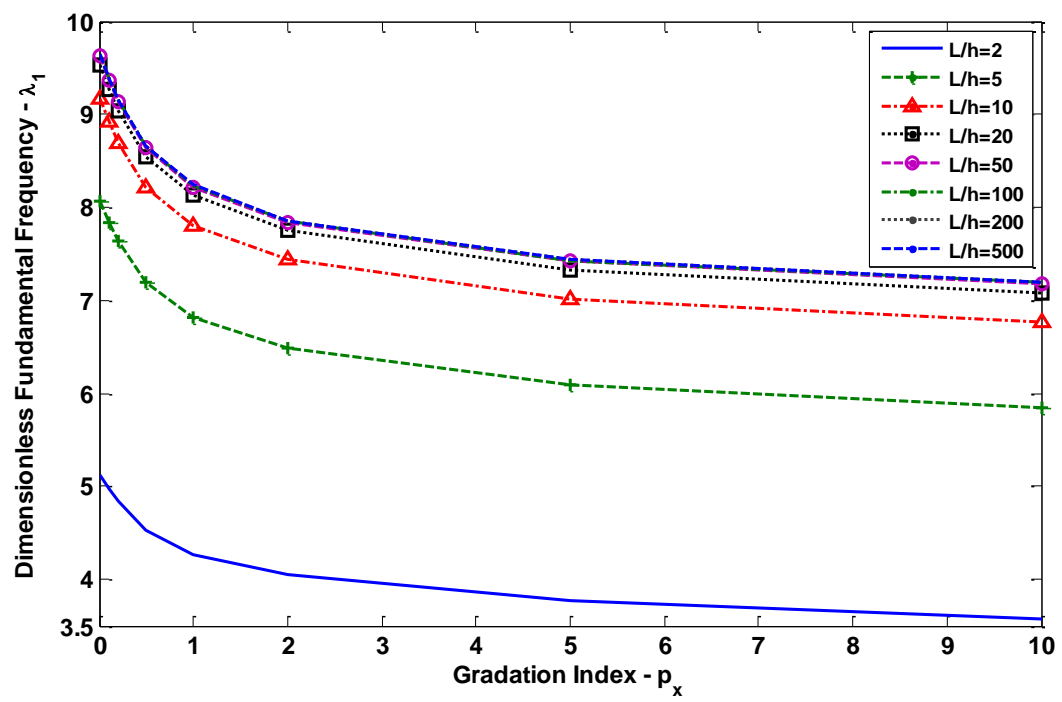

b) $\mathrm{p}_{\mathrm{z}}=1$

Figure 4. Variation of the dimensionless fundamental frequencies of $\mathrm{CC}$ two directional FGBs with respect to variation of gradient indexes and aspect ratios a) $p_{x}=1$ and b) $p_{z}=1$

Figures 6 to 9 examine the effect of the gradient indexes, aspect ratios and boundary conditions on the first critical buckling loads of the 2D-FGBs. As expected, as the aspect ratio increases, the dimensionless first critical buckling load increases for all types of BCs and the values of the gradient indexes studied in these examples. Besides, the dimensionless first critical buckling load decreases while the gradient index increases in any direction. It is clear that the highest first critical buckling loads are seen in CC beams followed by CS, SS and CF beams. It is also observed that the reduction in the dimensionless first critical buckling loads because of the gradient index variation in the $\mathrm{x}$ direction is more than the gradient index variation in the $\mathrm{z}$ direction for all boundary conditions and aspect ratios. Moreover, with the increase of the aspect ratio, the critical buckling loads become very close to each other after in the region, for SS and CS L/h $\geq 20, C F L / h \geq 10$ and $C C L / h \geq 30$. On the other hand, for $\mathrm{CC}$ beams, the effect of the shear deformation is significant in the region $\mathrm{L} / \mathrm{h} \leq 15$. 
Karamanlı / Anadolu Univ. J. of Sci. and Technology A-Appl. Sci. and Eng. 19 (2) - 2018

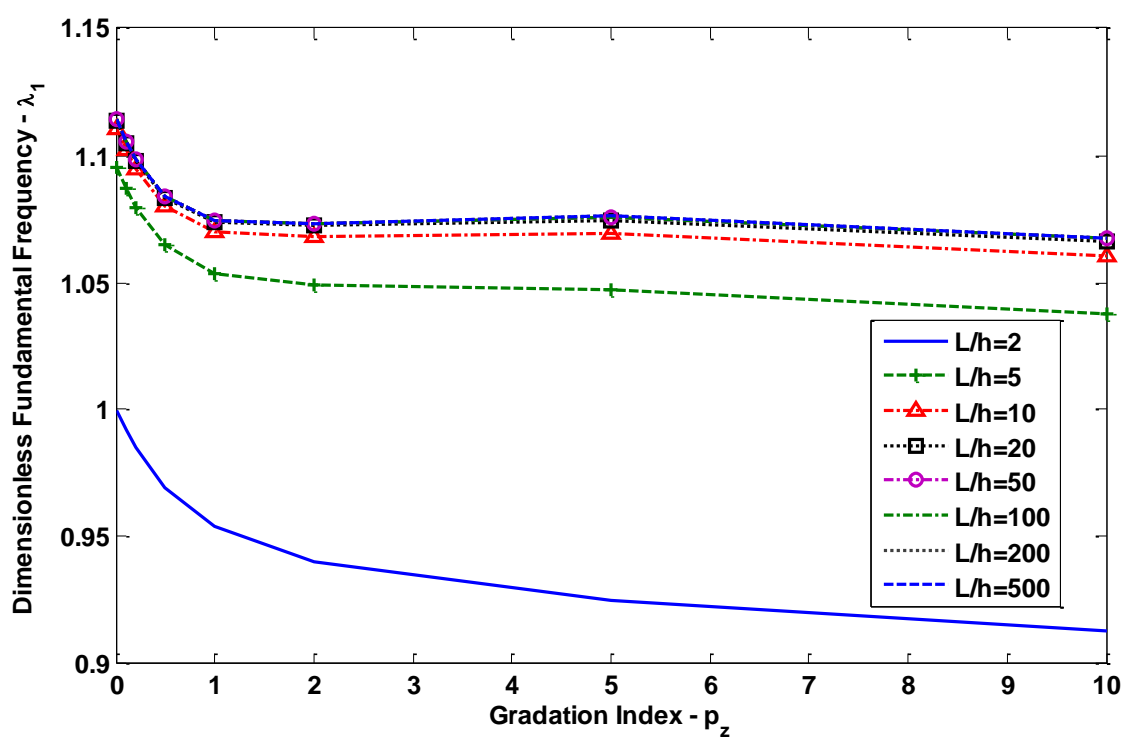

a) $\mathrm{p}_{\mathrm{x}}=1$

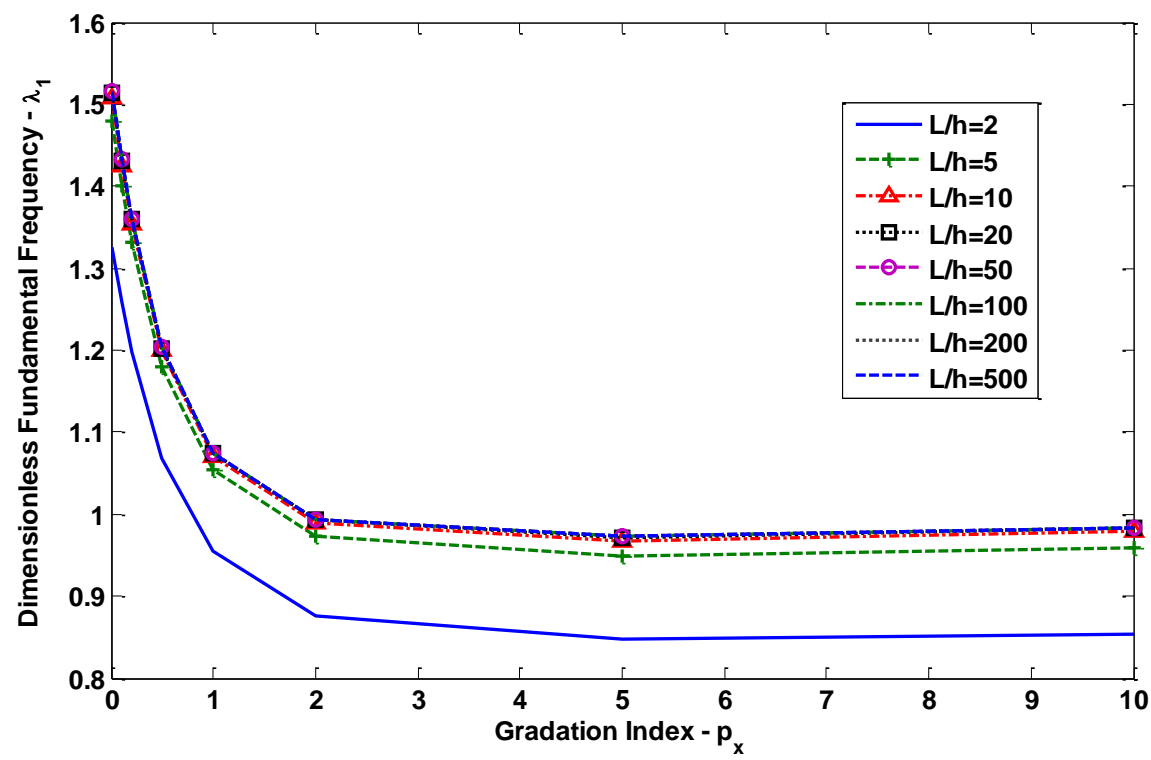

b) $\mathrm{p}_{\mathrm{z}}=1$

Figure 5. Variation of the dimensionless fundamental frequencies of CF two directional FGBs with respect to variation of gradient indexes and aspect ratios a) $\mathrm{p}_{\mathrm{x}}=1$ and b) $\mathrm{p}_{\mathrm{z}}=1$ 
Karamanlı / Anadolu Univ. J. of Sci. and Technology A-Appl. Sci. and Eng. 19 (2) - 2018

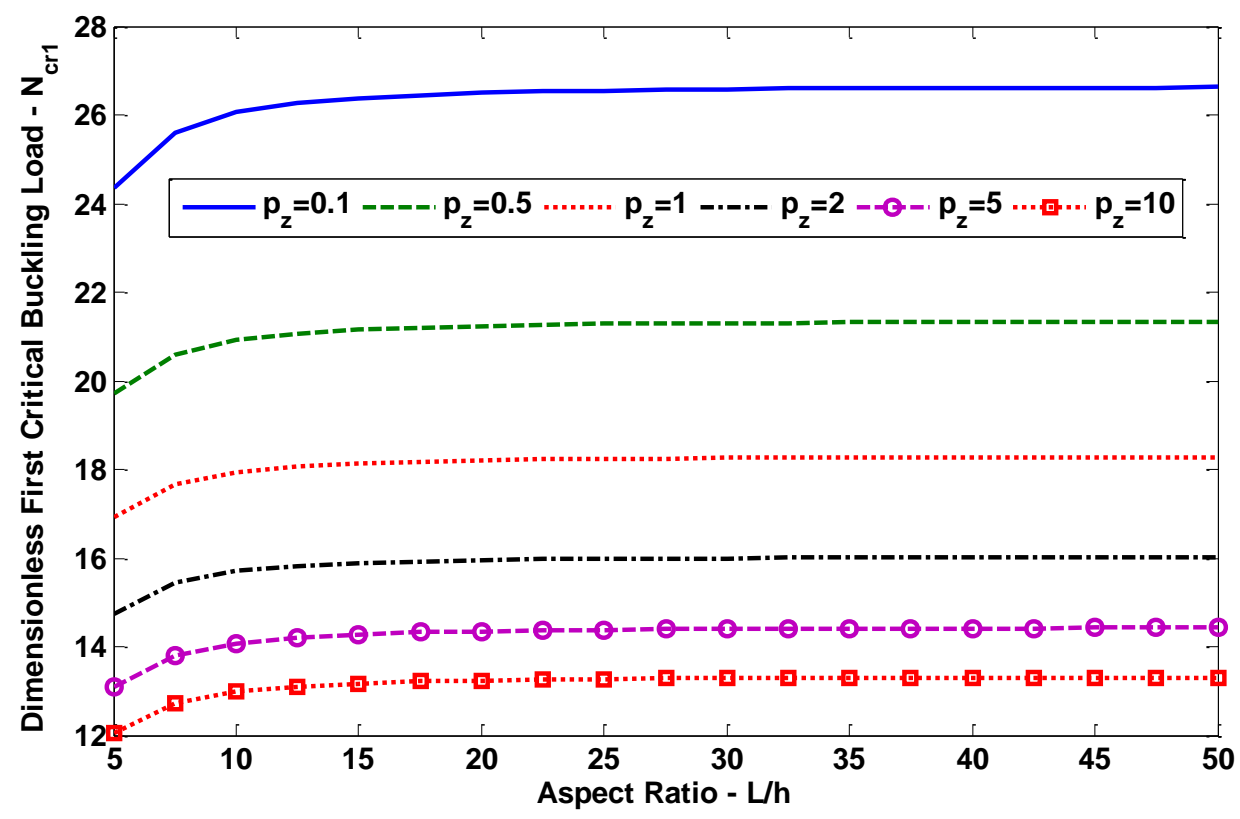

a) $\mathrm{p}_{\mathrm{x}}=1$

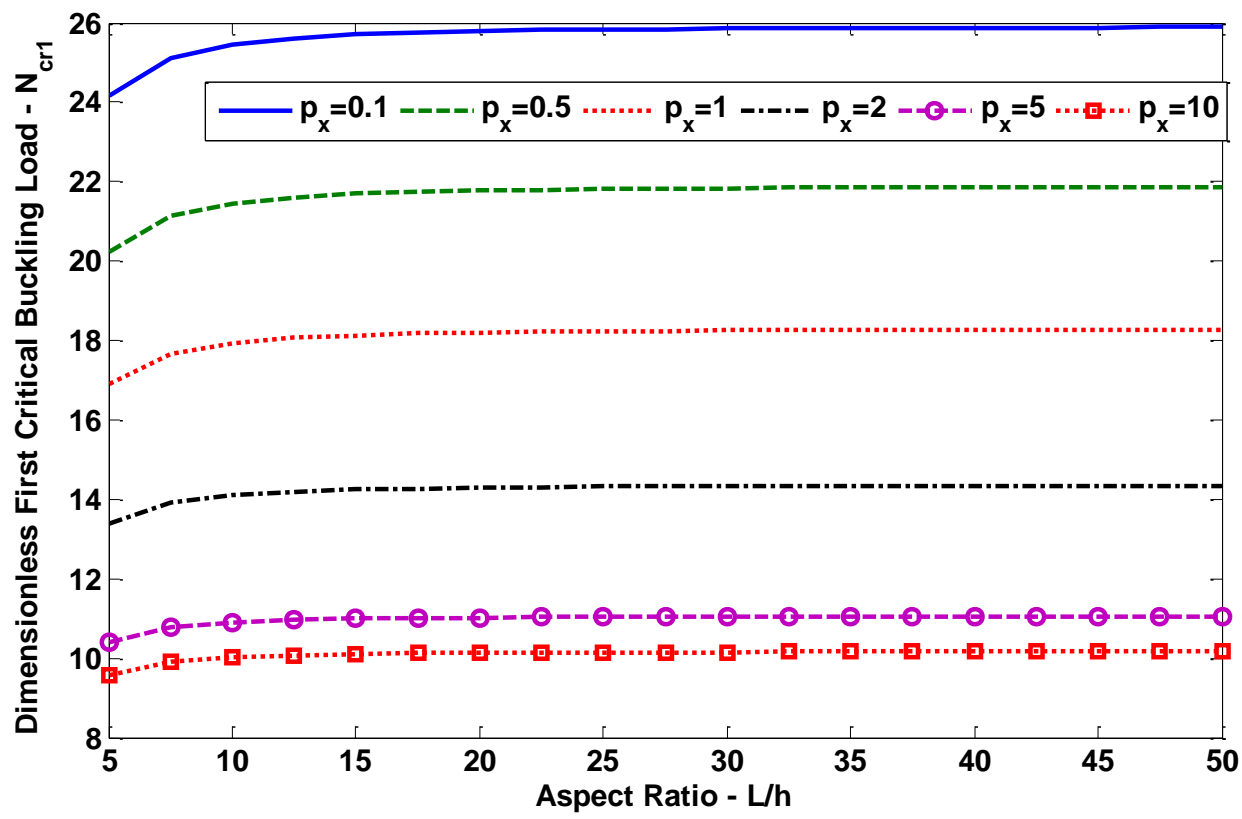

b) $\mathrm{p}_{\mathrm{z}}=1$

Figure 6. Variation of the dimensionless first critical buckling loads of SS two directional FGBs with respect to variation of gradient indexes and aspect ratios a) $p_{x}=1$ and b) $p_{z}=1$ 
Karamanlı / Anadolu Univ. J. of Sci. and Technology A-Appl. Sci. and Eng. 19 (2) - 2018

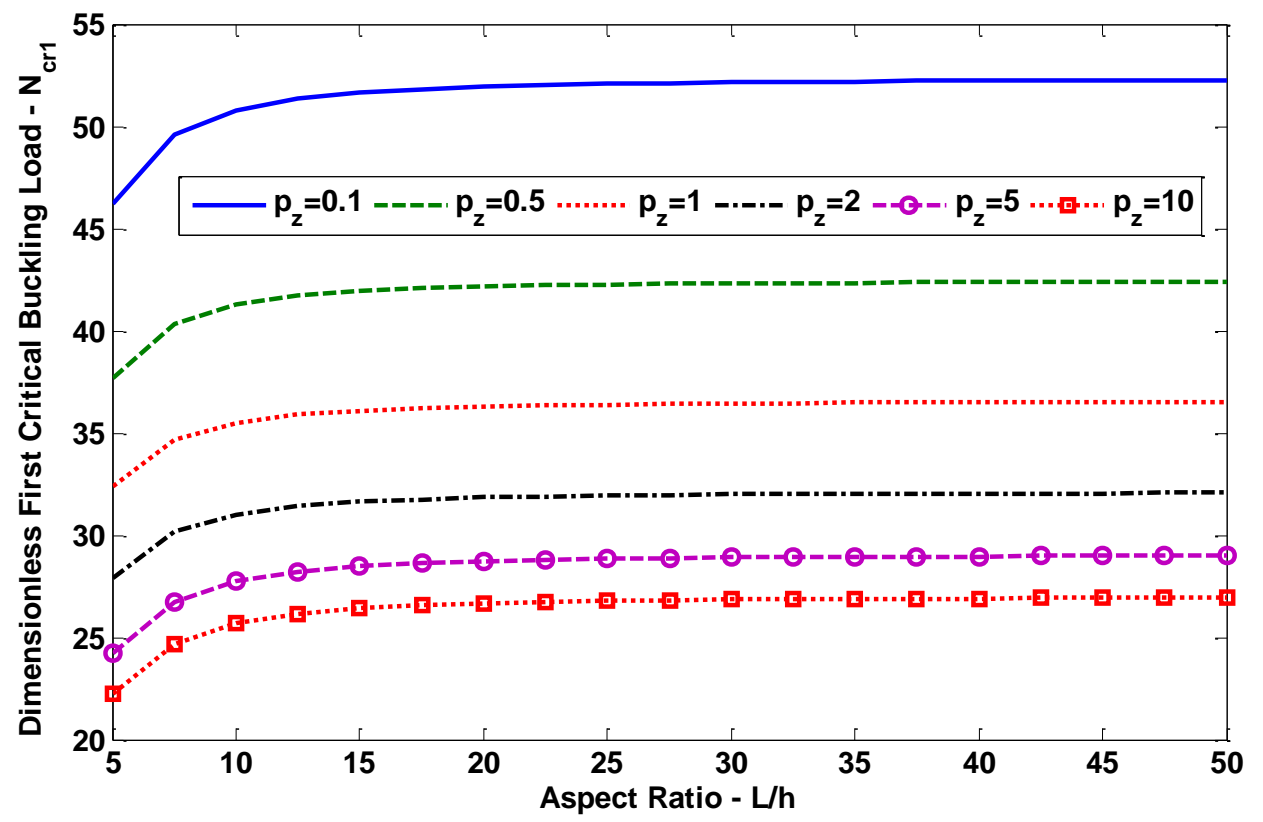

a) $\mathrm{p}_{\mathrm{x}}=1$

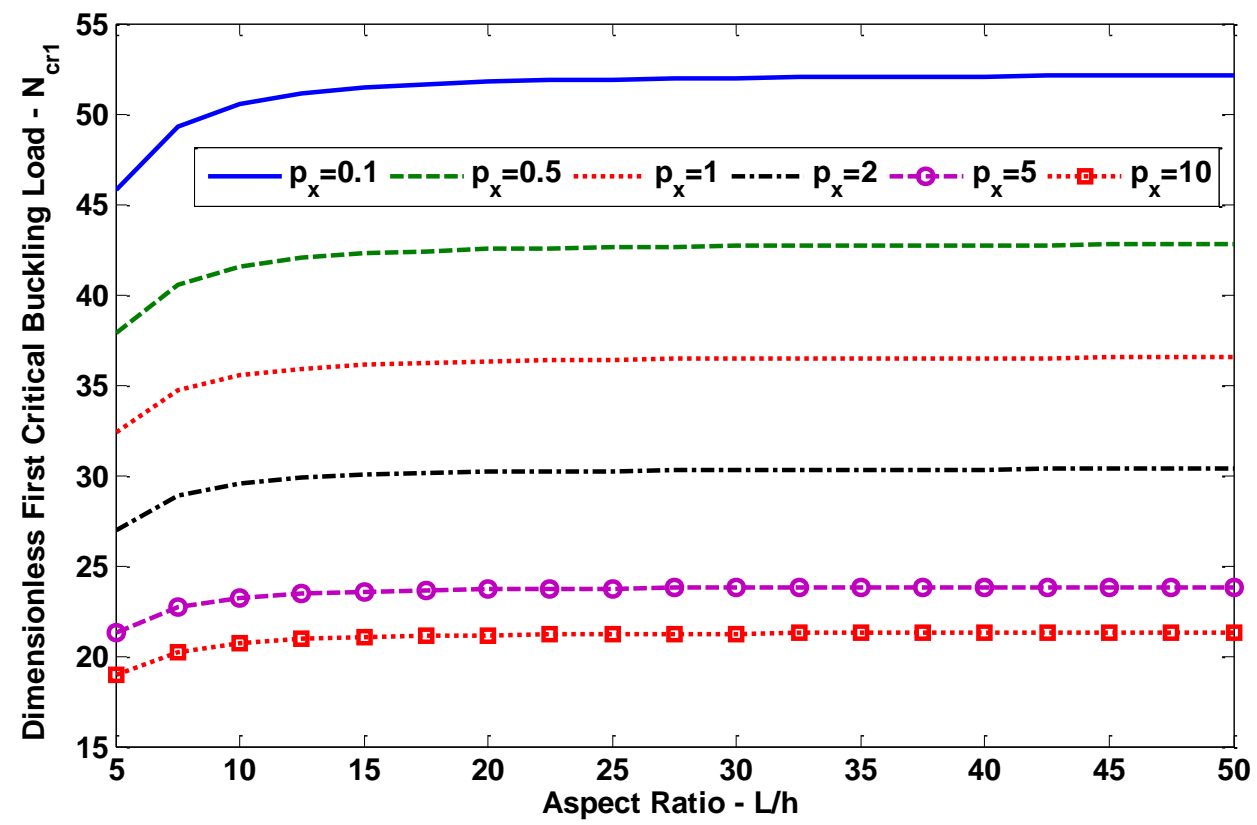

b) $\mathrm{p}_{\mathrm{z}}=1$

Figure 7. Variation of the dimensionless first critical buckling loads of CS two directional FGBs with respect to variation of gradient indexes and aspect ratios a) $\mathrm{p}_{\mathrm{x}}=1$ and b) $\mathrm{p}_{\mathrm{z}}=1$ 
Karamanlı / Anadolu Univ. J. of Sci. and Technology A-Appl. Sci. and Eng. 19 (2) - 2018

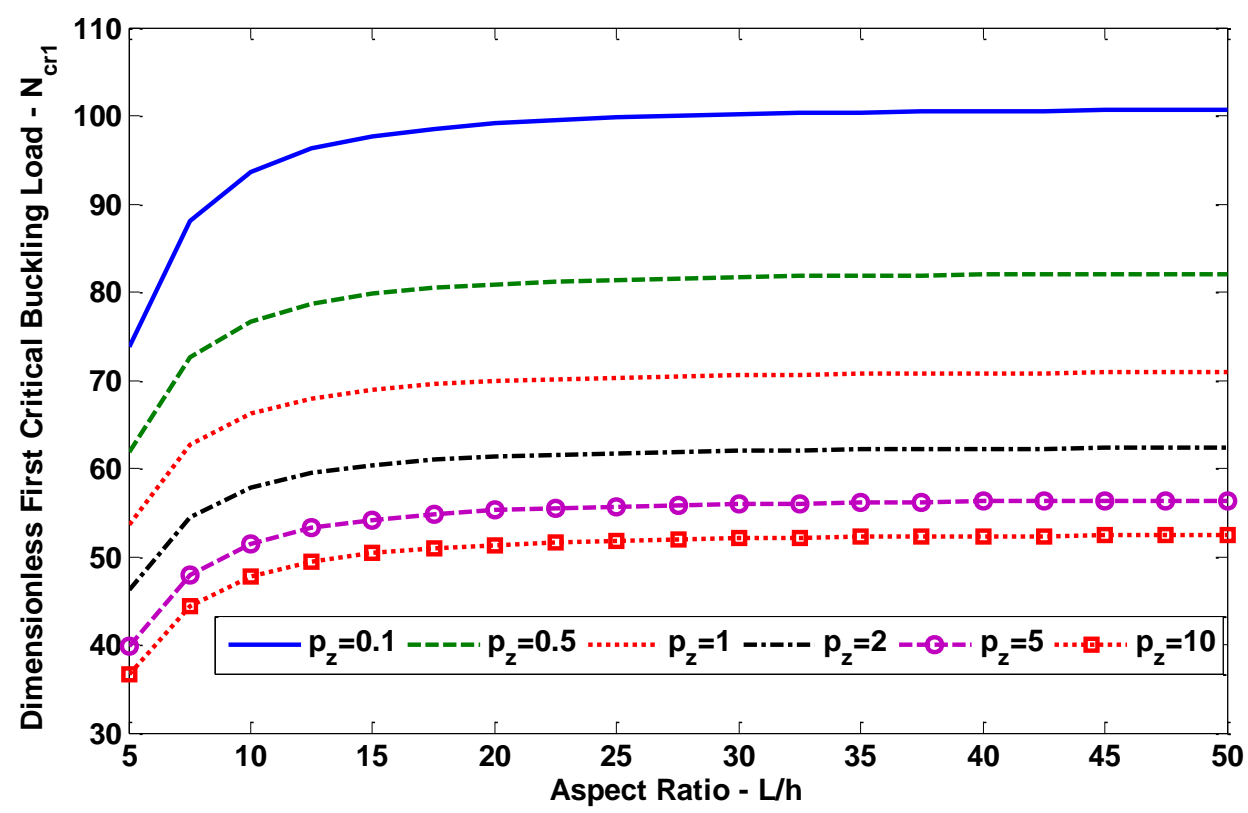

a) $\mathrm{p}_{\mathrm{x}}=1$

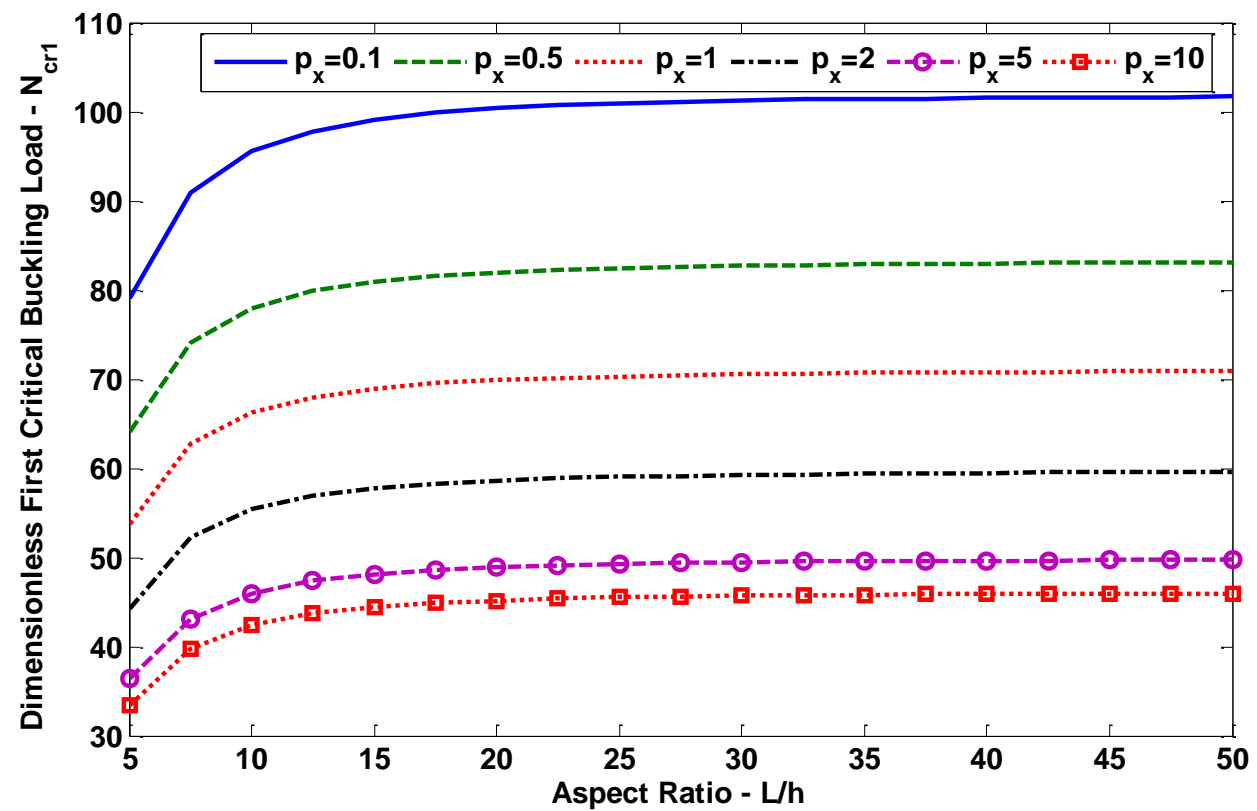

b) $\mathrm{p}_{\mathrm{z}}=1$

Figure 8. Variation of the dimensionless first critical buckling loads of CC two directional FGBs with respect to variation of gradient indexes and aspect ratios a) $\mathrm{p}_{\mathrm{x}}=1$ and b) $\mathrm{p}_{\mathrm{z}}=1$ 
Karamanlı / Anadolu Univ. J. of Sci. and Technology A-Appl. Sci. and Eng. 19 (2) - 2018

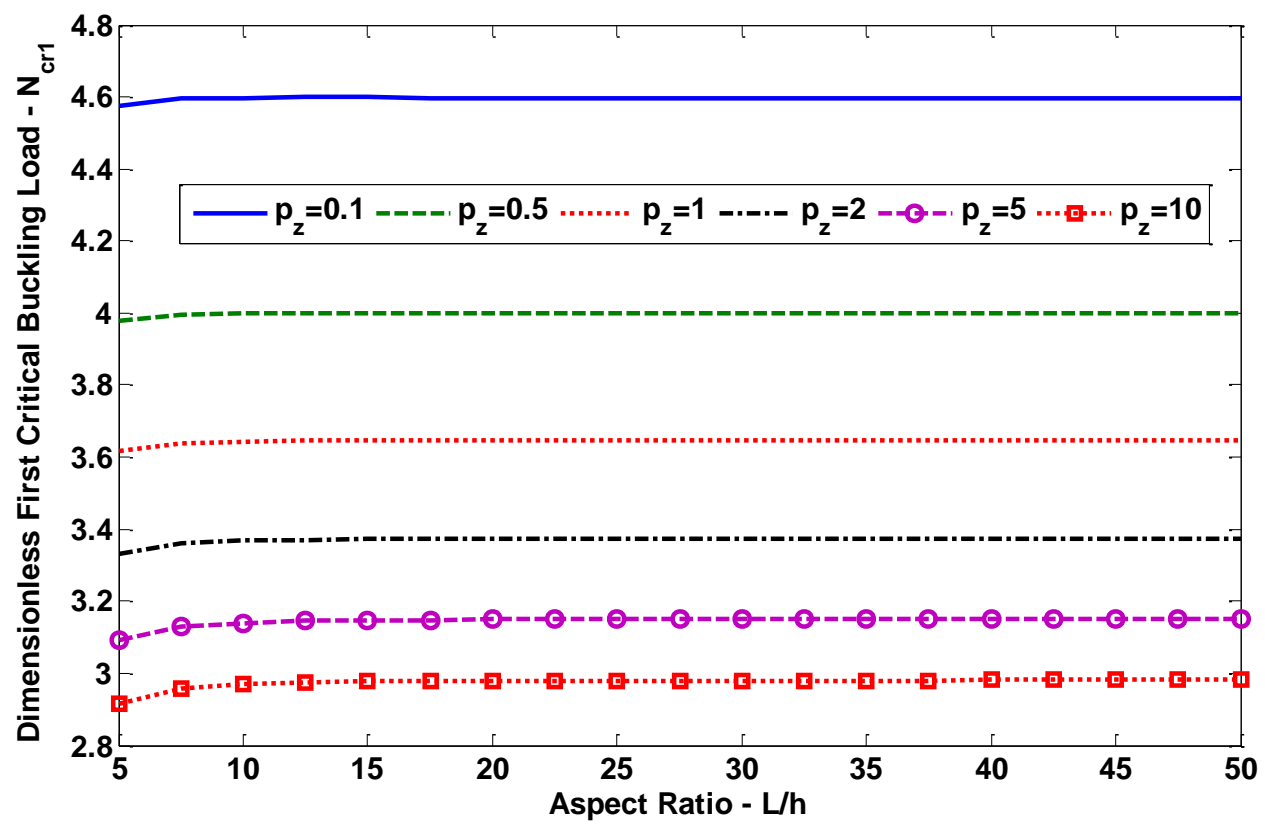

a) $\mathrm{p}_{\mathrm{x}}=1$

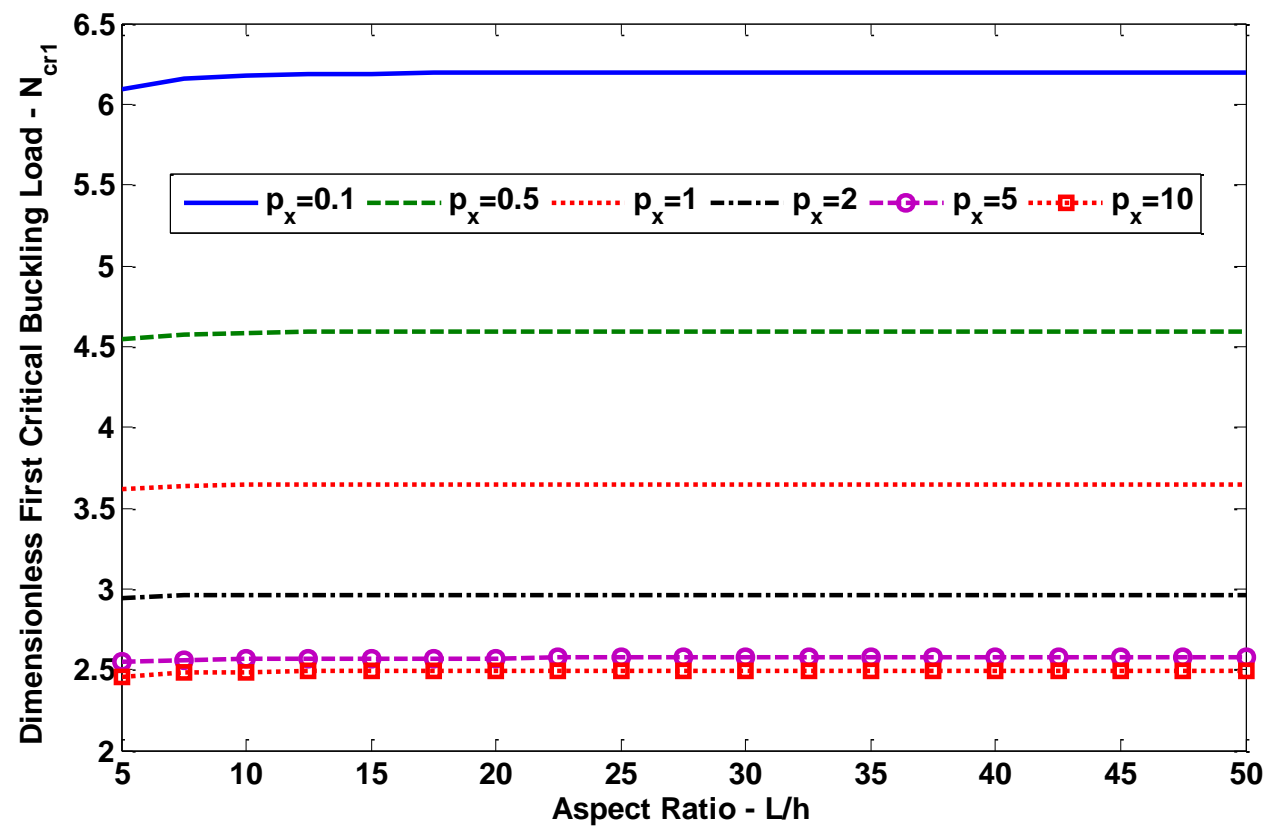

b) $\mathrm{p}_{\mathrm{z}}=1$

Figure 9. Variation of the dimensionless first critical buckling loads of CF two directional FGBs with respect to variation of gradient indexes and aspect ratios a) $p_{x}=1$ and b) $p_{z}=1$

The first four normalized vibration mode shapes of SS, CS, CC and CF 2D-FGBs with the gradient indexes, $\mathrm{p}_{\mathrm{z}}=1$ and $\mathrm{p}_{\mathrm{x}}=1$, are illustrated in Figures 10 to 13. Actually, the obtained mode shape is a quadruple mode shape. Since the small stretching deformation occurs, the resulting mode shape is referred as triply coupled mode, which is substantial involving axial, shear and bending deformations for all types of end conditions. The first four flexural normalized buckling mode shapes of the two directional FGBs for all type of boundary conditions are presented in Figure $14(\mathrm{~L} / \mathrm{h}=5, \mathrm{pz}=1$ and $\mathrm{px}=1$ ). One may expect that for a homogeneous $\mathrm{CC}$ beam the mode shapes are symmetric about the 
Karamanlı / Anadolu Univ. J. of Sci. and Technology A-Appl. Sci. and Eng. 19 (2) - 2018

midpoint of the beam. However, because of the material variation along the length of the beam the mode shapes become anti-symmetric about the midpoint of the 2D-FGB.

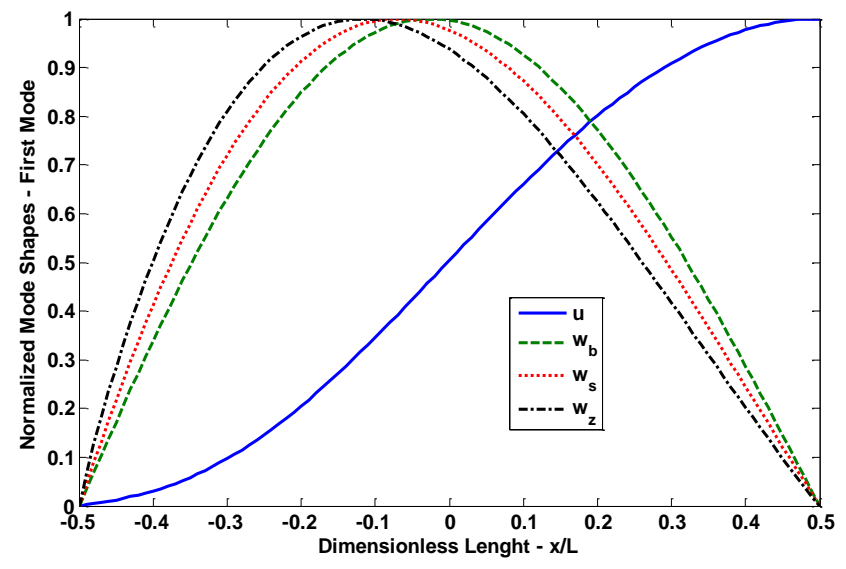

a) First Mode Shape

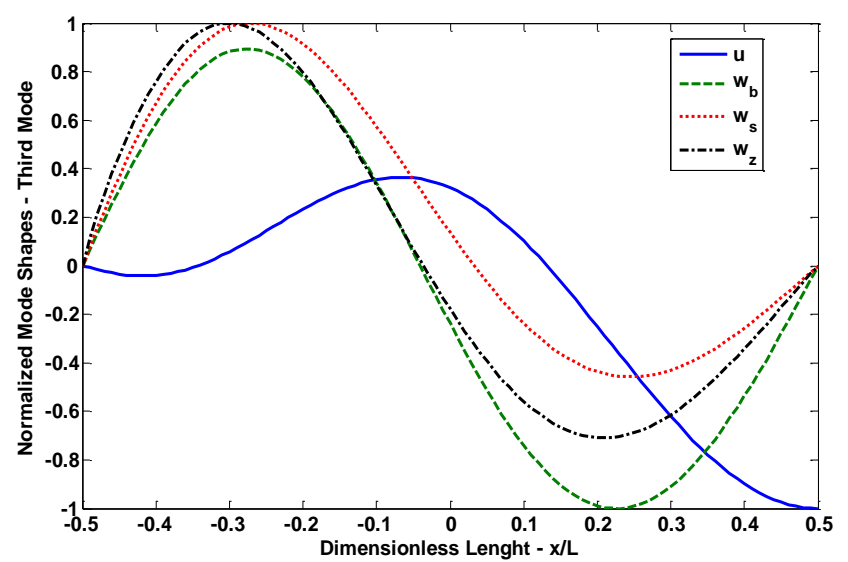

c) Third Mode Shape

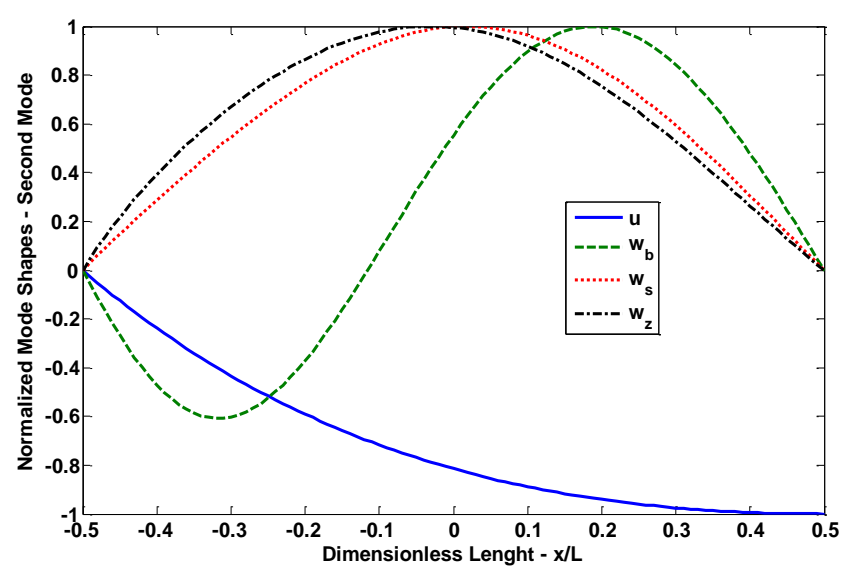

b) Second Mode Shape

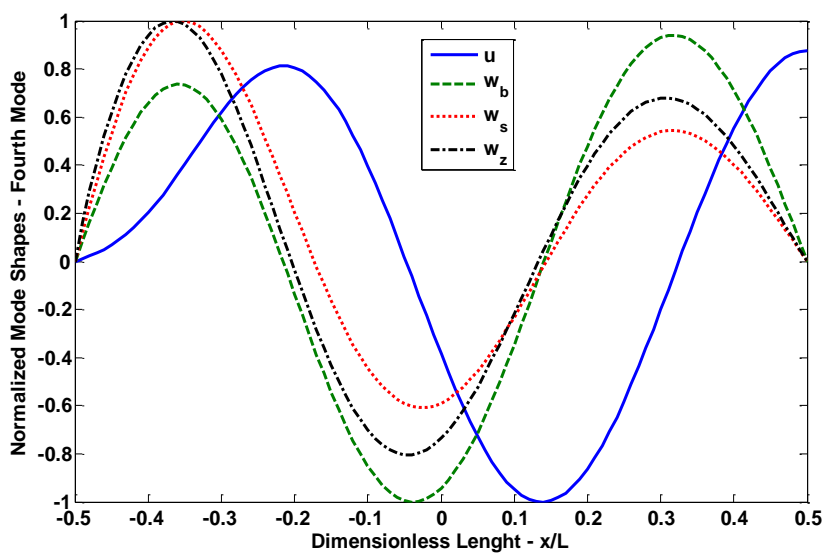

d) Fourth Mode Shape

Figure 10. First four normalized vibration mode shapes of $S S$ two directional FGBs $\left(L / h=5, p_{x}=1\right.$ and $\left.p_{z}=1\right)$ 
Karamanlı / Anadolu Univ. J. of Sci. and Technology A-Appl. Sci. and Eng. 19 (2) - 2018

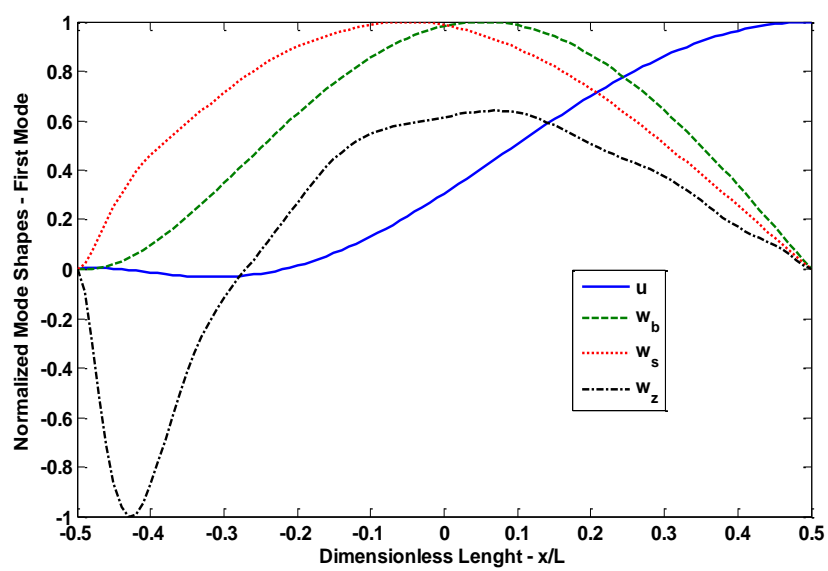

a) First Mode Shape

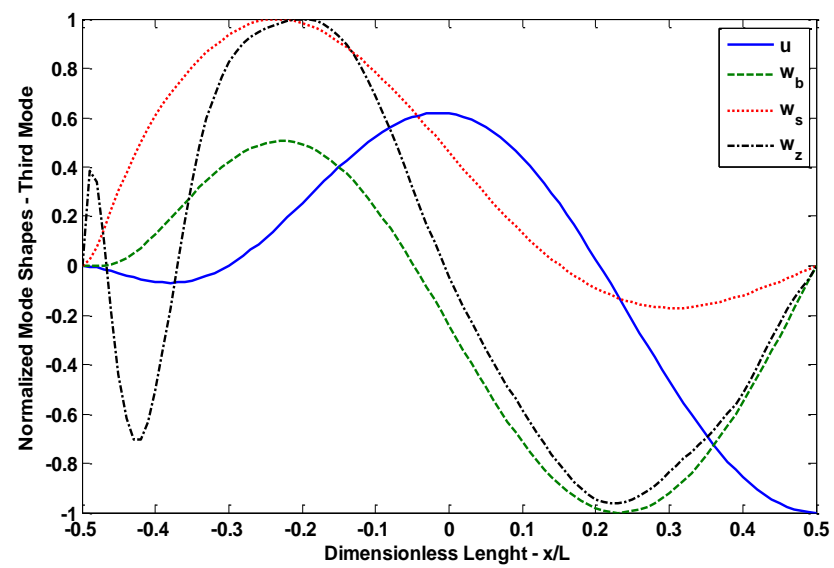

c) Third Mode Shape

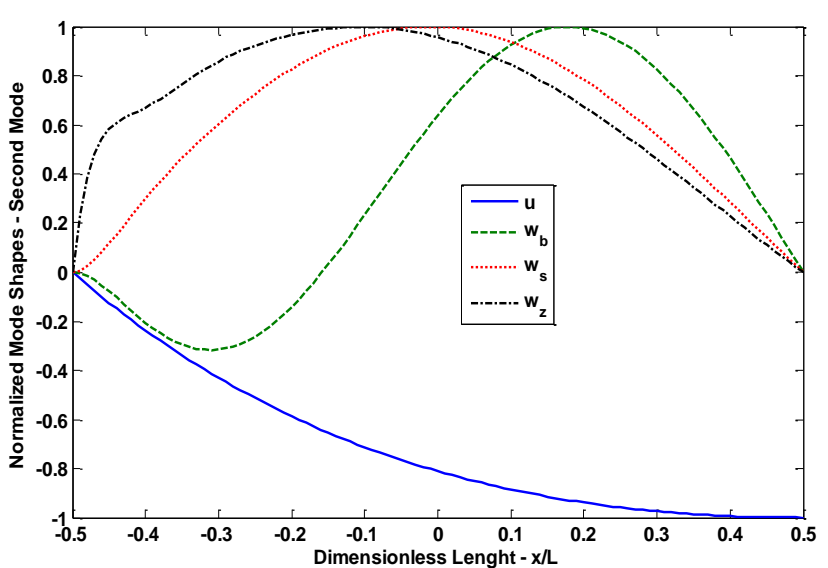

b) Second Mode Shape

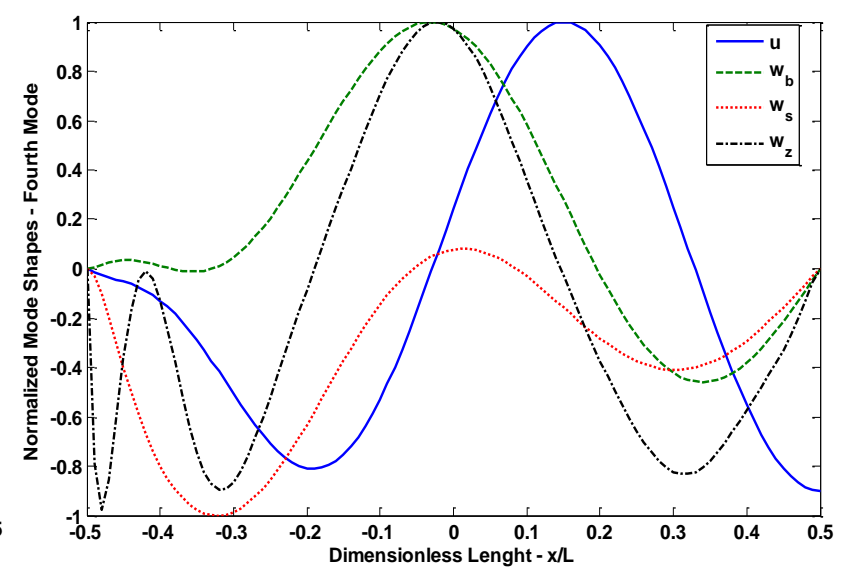

d) Fourth Mode Shape

Figure 11. First four normalized vibration mode shapes of CS two directional FGBs $\left(L / h=5, p_{x}=1\right.$ and $\left.p_{z}=1\right)$ 
Karamanlı / Anadolu Univ. J. of Sci. and Technology A-Appl. Sci. and Eng. 19 (2) - 2018

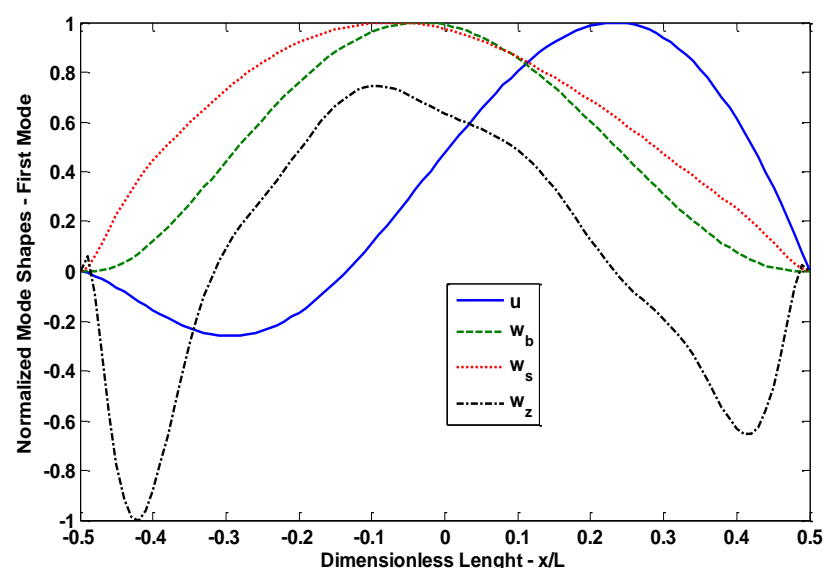

a) First Mode Shape

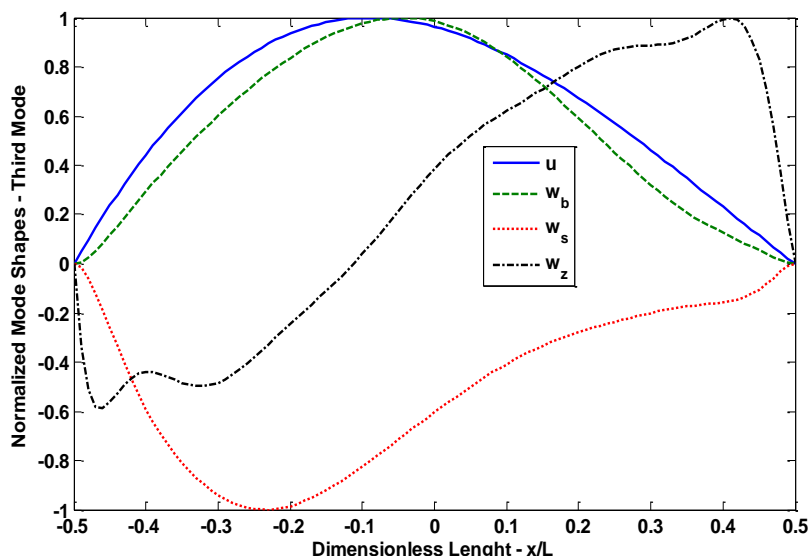

c) Third Mode Shape

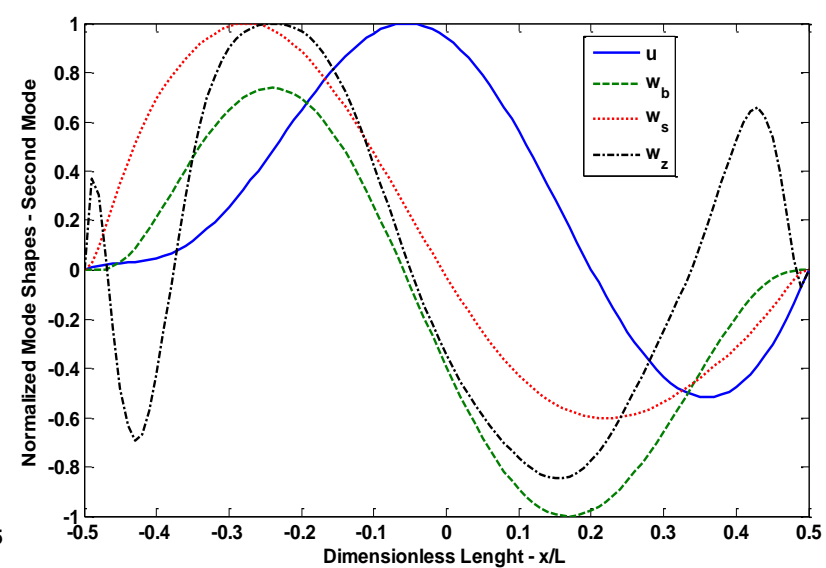

b) Second Mode Shape

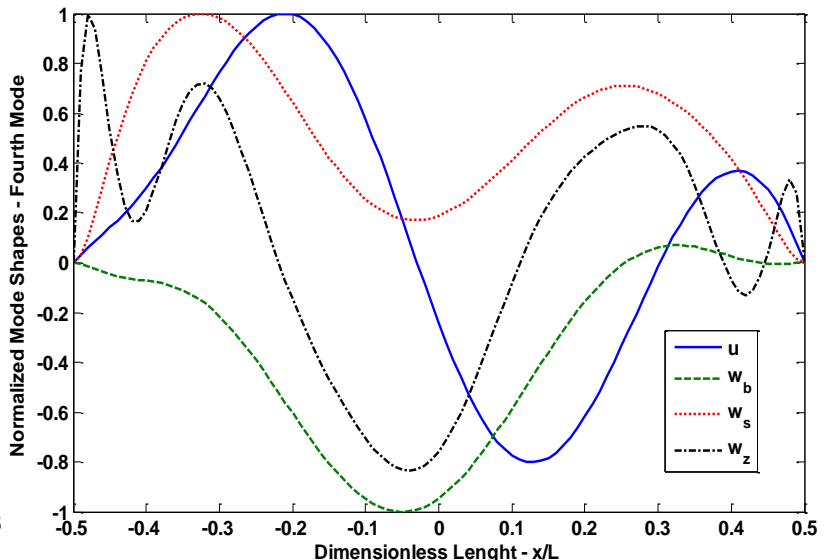

d) Fourth Mode Shape

Figure 12. First four normalized vibration mode shapes of $C C$ two directional FGBs $\left(L / h=5, p_{x}=1\right.$ and $\left.p_{z}=1\right)$ 
Karamanlı / Anadolu Univ. J. of Sci. and Technology A-Appl. Sci. and Eng. 19 (2) - 2018

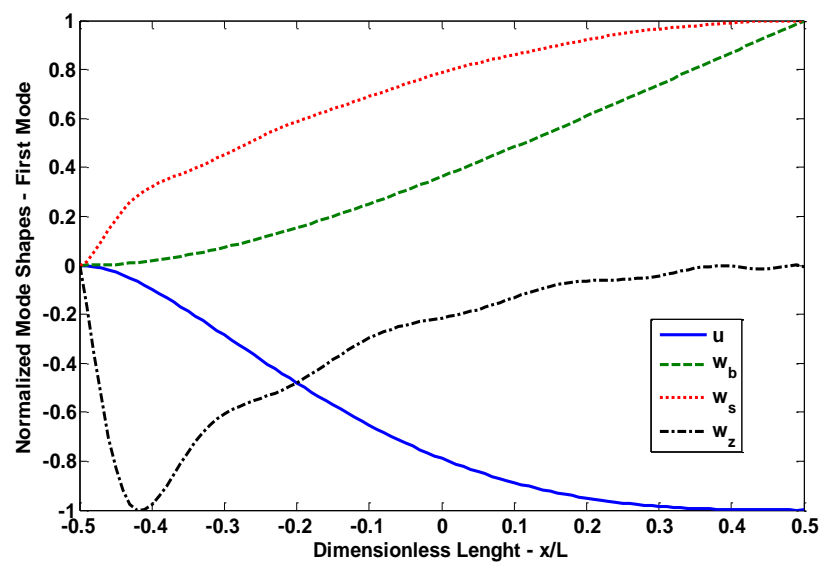

a) First Mode Shape

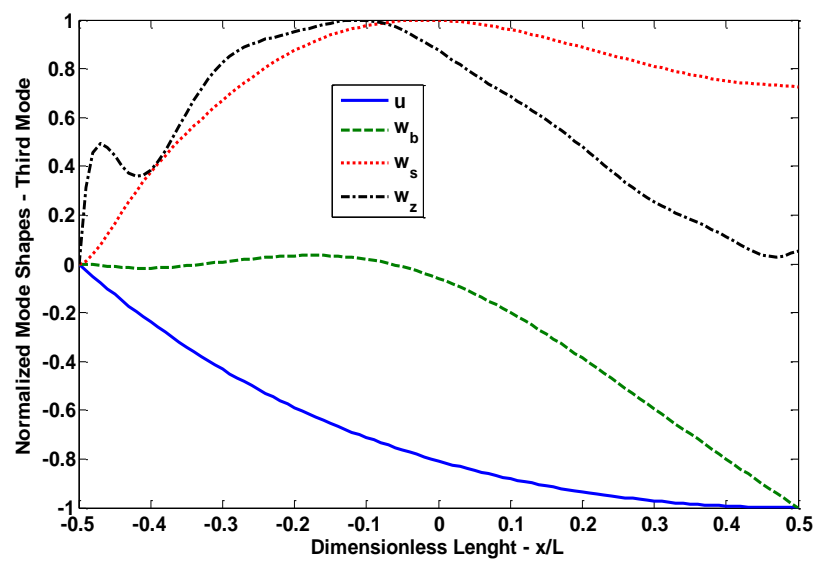

c) Third Mode Shape

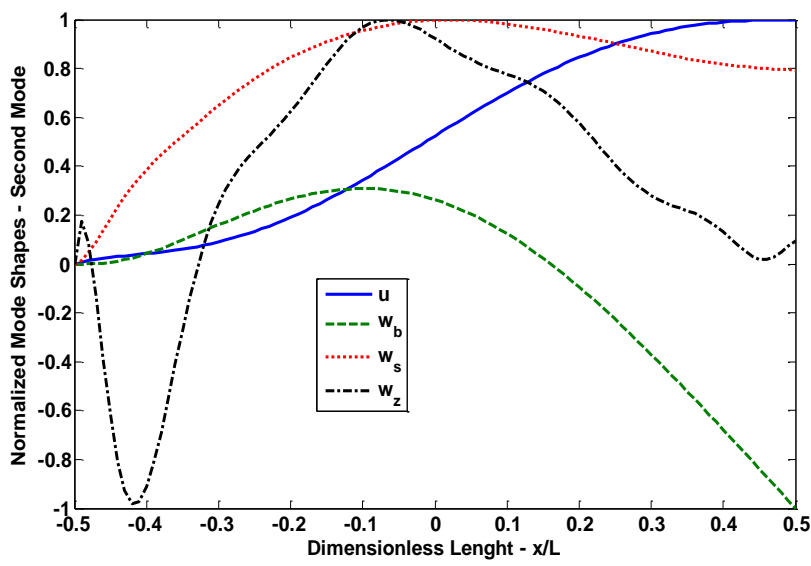

b) Second Mode Shape

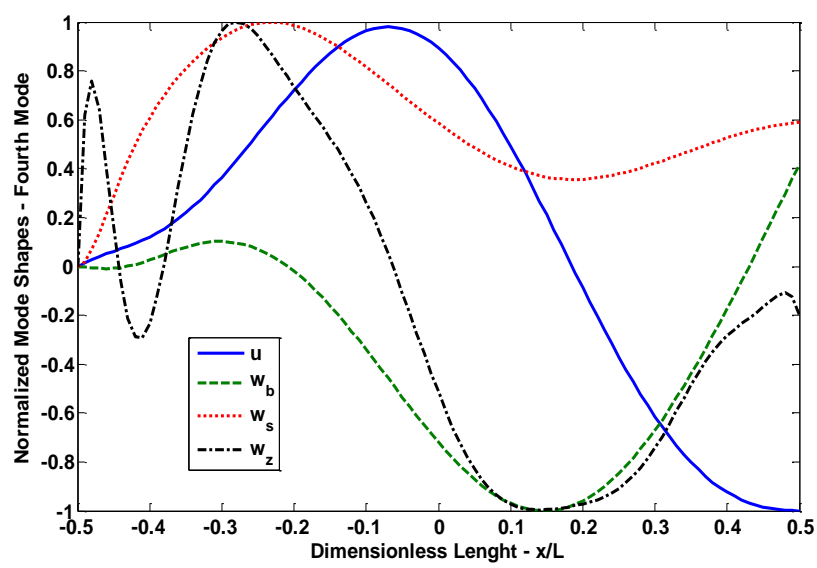

d) Fourth Mode Shape

Figure 13. First four normalized vibration mode shapes of $C F$ two directional $F G B s\left(L / h=5, p_{x}=1\right.$ and $\left.p_{z}=1\right)$ 


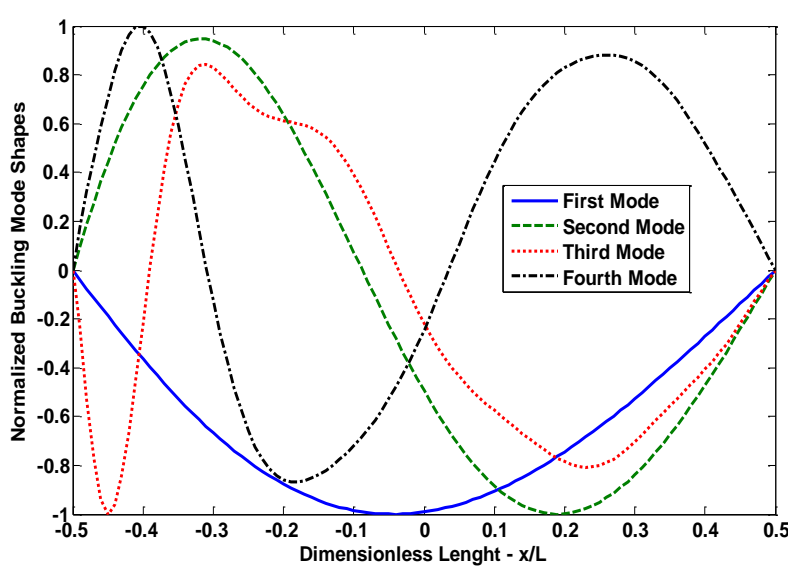

a) SS

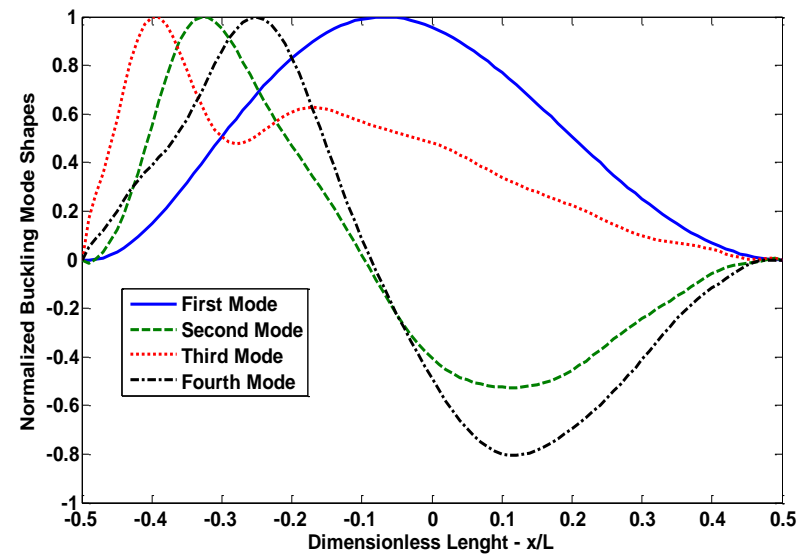

c) $\mathrm{CC}$

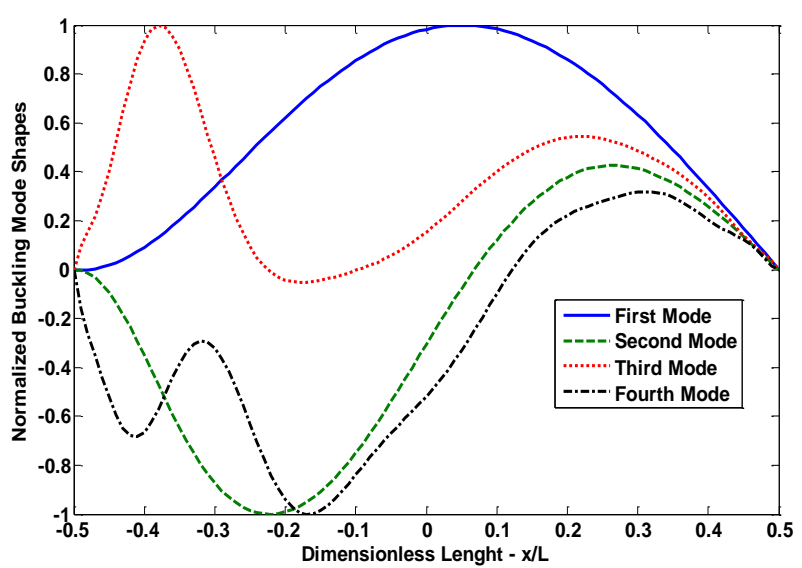

b) $\mathrm{CS}$

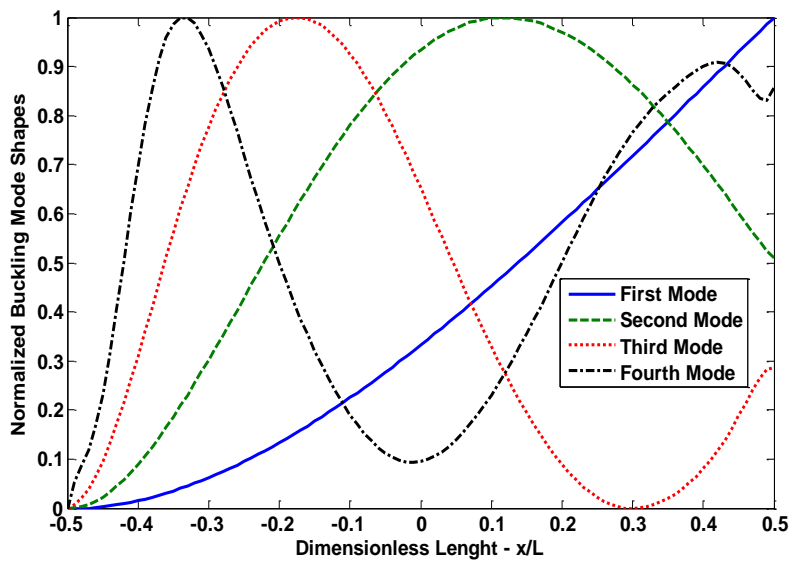

d) $\mathrm{CF}$

Figure 14. First four flexural $(\bar{W})$ normalized buckling mode shapes of two directional FGBs for various boundary conditions $\left(\mathrm{L} / \mathrm{h}=5, \mathrm{p}_{\mathrm{x}}=1\right.$ and $\left.\mathrm{p}_{\mathrm{z}}=1\right)$

\section{CONCLUSION}

In this paper, the free vibration and buckling behaviors of the two directional functionally graded beams having different boundary conditions are investigated by employing a four-unknown shear and normal deformation theory. The governing equations of motions are obtained via Lagrange equations in conjunction with polynomials added auxiliary functions that satisfy the boundary conditions. Analytical polynomial displacement solutions are derived for Simply supported - Simply supported (SS), Clamped-Simply supported (CS), Clamped - clamped (CC) and Clamped-free (CF) boundary conditions by employing various gradient indexes in both axial and thickness directions. The computed results in terms of dimensionless frequencies and critical buckling loads are compared with the results from previous studies. It is found that computed results show excellent agreement with previous ones. The effects of the boundary conditions, gradient indexes and aspect ratios on the dimensionless frequencies and critical buckling loads of the 2D-FGBs are discussed. Based on the extensive analysis, the main important results are given below:

- The dimensionless frequencies and buckling loads of the 2D-FGBs are greatly affected by the gradient indexes. However, the effect of the gradient index in the $\mathrm{x}$ direction is more significant than the gradient index in the $\mathrm{z}$ direction. 
- Increment of the gradient indexes, the dimensionless fundamental frequencies decrease because of decreasing the rigidity of the beam for SS, CS and CC beams.

- The effect of the mass on the dimensionless frequencies of the SS, CS and CC 2D-FGBs is a bit more dominant than the effect of the Young's modulus. The vibration behavior of the 2DFGBs with CF boundary condition is significantly affected with the variation of the mass and Young's modulus. This effect mainly depends on the gradient index value in the $\mathrm{x}$ direction, mode number and aspect ratio.

- The highest free vibration frequencies for 2D-FGBs are obtained while the CC boundary condition is employed. The lowest frequencies are observed for CF beams followed by SS and CS beams.

- Increment of the gradient indexes, the critical buckling load increase.

- The shear deformation effect becomes important as the buckling mode number increases. For all types of BCs, the relative difference between critical buckling loads increases as the buckling mode increases.

- As the aspect ratio increases, the shear deformation effect on the critical buckling loads of the $2 \mathrm{D}-\mathrm{FGBs}$ decreases. It is observed that CC 2D-FGB is much more sensitive to shear deformation effect than the other 2D-FGB models.

- A triply coupled mode shape which is substantial involving axial, shear and bending deformations for all types of end conditions is obtained.

- The highest first critical buckling loads are seen in CC beams followed by CS, SS and CF beams.

- To meet the design requirements, the vibration and buckling behaviors of the 2D-FGBs can be controlled by selecting suitable gradient indexes.

- Especially for thick beams, the shear deformation effect is very important and the proposed theory provides accurate results and is efficient in solving the vibration and buckling behaviors of the 2D-FGBs.

\section{REFERENCES}

[1] Chakraborty A., Gopalakrishnan S, Reddy JN. A new beam finite element for the analysis of functionally graded materials. Int J Mech Sci. 2003; 45(3) 519-539.

[2] Li X.F. A unified approach for analyzing static and dynamic behaviors of functionally graded Timoshenko and Euler-Bernoulli beams. J Sound Vib. 2008; 318 (4-5) 1210-1229.

[3] Li SR., Batra R.C. Relations between buckling loads of functionally graded Timoshenko and homogeneous Euler-Bernoulli beams. Compos Struct. 2013; 95 5-9.

[4] Nguyen TK., Vo TP., Thai H.T. Static and free vibration of axially loaded functionally graded beams based on the first-order shear deformation theory. Composites B. 2013; 55 147-57.

[5] Pradhan K, Chakraverty S. Free vibration of euler and Timoshenko functionally graded beams by Rayleigh-Ritz method. Composites B. 2013; 51 175-84. 
[6] Sina S, Navazi H, Haddadpour H. An analytical method for free vibration analysis of functionally graded beams, Mater Des. 2009; 30(3) 741-7.

[7] Aydogdu M, Taskin V. Free vibration analysis of functionally graded beams with simply supported edges. Mater Des. 2007; 28 1651-1656.

[8] Kapuria S, Bhattacharyya, M, Kumar, AN. Bending and free vibration response of layered functionally graded beams A theoretical model and its experimental validation. Compos Struct. 2008; 82(3) 390-402.

[9] Kadoli R., Akhtar K., Ganesan N. Static analysis of functionally graded beams using higher order shear deformation theory. Appl Math Model. 2008; 32 (12): 2509-2525.

[10] Benatta MA, Mechab I., Tounsi, A., Bedia, E.A.A. Static analysis of functionally graded short beams including warping and shear deformation effects. Comput Mater Sci. 2008; 44(2): 765773.

[11] Ben-Oumrane S, Abedlouahed T., Ismail M., Mohamed, B.B., Mustapha, M., Abbas, A.B.E.. A theoretical analysis of flexional bending of Al/Al2O3 S-FGM thick beams. Comput Mater Sci. 2009; 44(4): 1344-1350.

[12] Li XF, Wang BL, Han JC. A higher-order theory for static and dynamic analyses of functionally graded beams. Arch Appl Mech. 2010; 80: 1197-1212.

[13] Zenkour AM., Allam MNM, Sobhy M. Bending analysis of fg viscoelastic sandwich beams with elastic cores resting on Pasternaks elastic foundations. Acta Mech. 2010; 212: 233-252.

[14] Simsek M. Fundamental frequency analysis of functionally graded beams by using different higher-order beam theories. Nucl Eng Des. 2010; 240(4): 697-705.

[15] Thai HT, Vo TP. Bending and free vibration of functionally graded beams using various higherorder shear deformation beam theories. Int J Mech Sci. 2012; 62 (1): 57-66.

[16] Vo TP, Thai HT, Nguyen TK, Inam F. Static and vibration analysis of functionally graded beams using refined shear deformation theory. Meccanica. 2014; 49(1): 155-68.

[17] Vo TP, Thai HT, Nguyen TK, Maheri A, Lee J. Finite element model for vibration and buckling of functionally graded sandwich beams based on a refined shear deformation theory. Eng Struct. 2014; 64: 12-22.

[18] Nguyen TK, Nguyen TTP, Vo TP, Thai HT. Vibration and buckling analysis of functionally graded sandwich beams by a new higher-order shear deformation theory. Composites B. 2015; 76: $273-85$.

[19] Nguyen TK, Nguyen BD. A new higher-order shear deformation theory for static, buckling and free vibration analysis of functionally graded sandwich beams. J Sandwich Struct Mater. 2015; 17(6): 613-31.

[20] Carrera E, Giunta G, Petrolo M. Beam structures classical and advanced theories. John Wiley \& Sons; 2011. 
[21] Giunta G, Belouettar S, Carrera E. Analysis of FGM beams by means of classical and advanced theories. Mech Adv Mater Struct. 2010; 17(8): 622-35.

[22] Mashat DS., Carrera E, Zenkour AM, Khateeb, S.A.A., Filippi, M. Free vibration of FGM layered beams by various theories and finite elements. Composites B. 2014; 59: 269-78.

[23] Filippi M., Carrera, E., Zenkour A.M. Static analysis of FGM beams by various theories and finite elements. Composites B. 2015; 72: 1-9.

[24] Vo, T.P., Thai H.T., Nguyen T.K., Inam, F., Lee, J. A quasi-3D theory for vibration and buckling of functionally graded sandwich beams. Compos Struct. 2015; 119: 1-12.

[25] Vo T.P., Thai, H.T., Nguyen T.K., Inam, F., Lee, J. Static behaviour of functionally graded sandwich beams using a quasi-3D theory, Composites B. 2015; 68: 59-74.

[26] Mantari J.L., Yarasca J. A simple and accurate generalized shear deformation theory for beams, Compos Struct. 2015; 134: 593-601.

[27] Mantari, J.L. A refined theory with stretching effect for the dynamics analysis of advanced composites on elastic foundation. Mech Mater. 2015; 86: 31-43.

[28] Mantari J.L. Refined and generalized hybrid type quasi-3D shear deformation theory for the bending analysis of functionally graded shells, Composites B. 2015; 83: 142-52.

[29] Nguyen T.K., Vo T.P., Nguyen B.D., Lee J. An analytical solution for buckling and vibration analysis of functionally graded sandwich beams using a quasi-3D shear deformation theory. Compos. Struct. 2016; 156: 238-252.

[30] A. Frikha, A. Hajlaoui, M. Wali, F. Dammak. A new higher order C0 mixed beam element for FGM beams analysis, Composites B. 2016; 106: 181-9.

[31] Nemat-Alla M. Reduction of thermal stresses by developing two-dimensional functionally graded materials. Int. Journal of Solids and Structures. 2003; 40: 7339-7356.

[32] Goupee A.J., Vel S.S. Optimization of natural frequencies of bidirectional functionally graded beams. Struct. Multidisc. Optim. 2006; 32: 473-484.

[33] Lü C.F., Chen W.Q., Xu R.Q., Lim C.W. Semi-analytical elasticity solutions for bidirectional functionally graded beams. Int. Journal of Solids and Structures. 2008; 45: 258-275.

[34] Zhao L., Chen W.Q., Lü C.F. Symplectic elasticity for two-directional functionally graded materials. Mech. Mater. 2012; 54: 32-42.

[35] Simsek M. Bi-Directional functionally graded materials (BDFGMs) for free and forced vibration of Timoshenko beams with various boundary conditions. Compos. Struct. 2015; 141: 968-978.

[36] Simsek M. Buckling of Timoshenko beams composed of two-dimensional functionally graded material (2D-FGM) having different boundary conditions. Compos. Struct. 2016; 149: 304-314.

[37] Karamanli A. Elastostatic analysis of two-directional functionally graded beams using various beam theories and Symmetric Smoothed Particle Hydrodynamics method. Compos. Struct. 2017; 160: 653-669. 
Karamanlı / Anadolu Univ. J. of Sci. and Technology A-Appl. Sci. and Eng. 19 (2) - 2018

[38] Nazargah M. Fully coupled thermo-mechanical analysis of bi-directional FGM beams using NURBS isogeometric finite element approach. Aerospace Science and Technology. 2015; 45: 154-164.

[39] Pydah A., Batra R.C. Shear deformation theory using logarithmic function for thick circular beams and analytical solution for bi-directional functionally graded circular beams. Compos. Struct. 2017; 172: 45-60.

[40] Karamanli A. Bending behaviour of two directional functionally graded sandwich beams by using a quasi-3d shear deformation theory. Compos. Struct. 2017; 174: 70-86.

[41] Zafarmand H., Hassani B. Analysis of two-dimensional functionally graded rotating thick disks with variable thickness. Act Mech. 2014; 225: 453-464.

[42] Nguyen D.K., Nguyen Q.H., Tran T.T., Bui V.T. Vibration of bi-dimensional functionally graded Timoshenko beams excited by a moving load. Act Mech. 2017; 228: 141-155.

[43] Haciyev V.C., Sofiyev A.H., Kuruoğlu V.T. Free bending vibration analysis of thin bidirectionally exponentially graded orthotropic rectangular plates resting on two-parameter elastic foundations. Compos. Struct. 2018; 184: 372-377. 